\title{
Final Report to the Strategic Environmental Research and Development Program on Near-Net Shape Casting of Uranium-6\% Niobium Alloys
}

\author{
William H. Gourdin \\ Project Leader

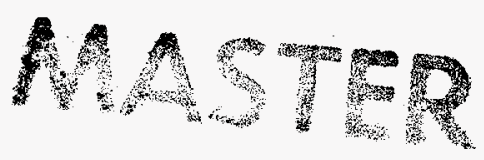 \\ November 29, 1994
}

\section{Introduction}

Fabrication methods traditionally used in the fabrication of depleted uranium parts within the Department of Energy (DOE) are extremely wasteful, with only $3 \%$ of the starting material actually appearing as finished product. The current effort, funded by the Strategic Environmental Research and Development Program (SERDP) at Los Alamos National Laboratory (LANL), Sandia National Laboratories, Albuquerque (SNLA), and Lawrence Livermore National Laboratory (LLNL), was conceived as a means to drastically reduce this inefficiency and the accompanying waste by demonstrating the technology to cast simple parts close to their final shape in molds made from a variety of materials. As a part of this coordinated study, LLNL was given, and has achieved, two primary objectives: (1) to demonstrate the feasibility of using refractory metal for reusable molds in the production of castings of uranium $-6 \mathrm{wt} \%$ niobium alloy (U-6Nb); and (2) to demonstrate the utility of detailed simulations of thermal and fluid flow characteristics in the understanding and improvement of the near-net shape casting process. In both cases, our efforts were focused on a flat plate castings, which serve as simple prototypical parts. This report summarizes the results of LLNL work in each area.

\section{Casting U-6Nb into Refractory Metal Molds (W. H. Gourdin)}

\section{Mold Design}

Figure 1 is a drawing of the tantalum-10 wt $\%$ tungsten mold we fabricated for this study. Metal enters the mold through a tantalum funnel secured to the top, and the casting therefore occurs in an "edge-on" configuration. The mold cavity is approximately $6.4 \mathrm{~mm}(0.25 \mathrm{in}$.) thick when the mold halves are joined and has a slight $\left(0.5^{\circ}\right)$ taper from top to bottom. A cylindrical header bar $20 \mathrm{~mm}$ in diameter at the top of the plate provides a reservoir of liquid metal to fill shrinkage cavities that form during solidification. The mold halves are held together with tantalum bolts coated with hafnium oxide, which serves as a lubricant and release agent. Because tantalum and its alloys are expensive and difficult to machine, the mold was assembled and welded together from plate stock of appropriate thicknesses. Material was then removed only from the mold cavity itself, thereby minimizing the amount of machining and waste. The thinness of the mold body, however, allows some warping to occur. Even though the mating surfaces were lapped flat to promote a good seal, 


\section{DISCLAIMER}

This report was prepared as an account of work sponsored by an agency of the United States Government. Neither the United States Government nor any agency thereof, nor any of their employees, make any warranty, express or implied, or assumes any legal liability or responsibility for the accuracy, completeness, or usefulness of any information, apparatus, product, or process disclosed, or represents that its use would not infringe privately owned rights. Reference herein to any specific commercial product, process, or service by trade name, trademark, manufacturer, or otherwise does not necessarily constitute or imply its endorsement, recommendation, or favoring by the United States Government or any agency thereof. The views and opinions of authors expressed herein do not necessarily state or.reflect those of the United States Government or any agency thereof. 


\section{DISCLAMMER}

Portions of this document may be illegible in electronic image products- Images are produced from the best available original document. 
some gaps at the parting line were apparent when the mold was assembled. These were sealed with a water-based yttria (yttrium oxide) slurry. ${ }^{1}$

Although tantalum-tungsten alloys have very good high-temperature strength, they are subject to grain boundary attack by liquid uranium. The interior surfaces of the mold must therefore be protected by a coating or surface treatment. Experience with the tantalum funnel during preliminary castings prepared with graphite molds (discussed below) indicated that a plasma sprayed coating of yttria was quite durable on a tantalum substrate. The adherence of the coating is no doubt aided by the close match between the thermal expansion coefficient of tantalum $\left(9.1 \times 10^{-6} \mathrm{~K}^{-1}\right.$ at $\left.1000^{\circ} \mathrm{C}\right)$ and yttria $\left(7.4 \times 10^{-6} \mathrm{~K}^{-1}\right.$ at $\left.1000^{\circ} \mathrm{C}\right)$. The narrow end of this funnel was exposed to the erosive effects of the entering liquid metal stream, but the protective yttria coating showed little deterioration with repeated use. To test the feasibility of using plasmasprayed yttria as the primary barrier coating, coupons of Ta-10W were plasma coated and placed on the sides and bottom of a graphite mold with the same configuration as the metal mold (see Fig. 2). The placement of the coupons was chosen to subject the coating to the high-temperature erosive environment produced by the liquid-metal stream as it enters the mold, strikes the bottom, and is directed laterally to fill the mold cavity. A 6.1-kg charge was poured into this specially prepared mold, and the coupons were then extracted from the casting. In all cases, the coating appeared to offer satisfactory protection to the Ta-10W substrates, which released easily from the uranium and showed no obvious signs of liquid-metal attack. On the basis of this result, plasma-sprayed yttria was selected as the primary barrier coating for the Ta-10W mold. As indicated previously, a waterbased yttria slurry was applied during and after mold assembly to seal gaps at the parting line.

Prior to casting uranium alloy into the metal mold, several preliminary castings were prepared in a comparable graphite (ATJ grade) mold shown in Fig. 2. The cavity of the graphite mold was identical to that of the metal mold (as were many of the external dimensions), but the thickness of the graphite ( $31.75 \mathrm{~mm}=1.25 \mathrm{in}$.) was considerably larger in order to provide necessary mechanical strength. The mating surfaces of the graphite mold were lapped flat to provide the best possible sealing surface, and because of the dimensional stability of the graphite, no warping occurred. As a result, there was no need to apply a yttria slurry at the parting line. The thermal expansion coefficient of the graphite $\left(7.2 \times 10^{-6} \mathrm{~K}^{-1}\right)$ matched that of tantalum well, so that tantalum bolts could be used to hold the mold halves together without gaps appearing at elevated temperatures. As with the metal mold, a coating of plasma-sprayed yttria was applied to the cavity surfaces. However, in the case of graphite, this coating served merely as a release agent and a barrier to minimize carbon entrainment into the casting.

\section{Foundry Description}

The LLNL depleted uranium foundry, shown in Fig. 3, is a bottom pour design. The crucible is assembled above the mold on a movable cart in an air-draft hood enclosure. When ready to make a casting, the cart is wheeled into a vacuum chamber at one end of the hood. The mold and crucible are heated inductively with separate power supplies. The crucible, made of yttria-coated graphite, has a $50-\mathrm{kg}$ maximum capacity and is heated by a $100-\mathrm{kW}$ power supply that operates at $3 \mathrm{kHz}$ with a 9-turn, water-cooled, copper coil. Foamed zirconia (zirconium dioxide) refractory ${ }^{2}$ is used as radiative shielding and surrounds the crucible. An yttriacoated graphite stopper rod, which extends vertically through the melt, plugs a $31.75-\mathrm{mm}$ (1.25-in.) orifice at the bottom of the crucible. Yttria slurry applied during assembly provides a reliable seal between the ball-end of the stopper rod and the orifice rim. At pour time, the rod is withdrawn by a remotely actuated air cylinder.

The mold is heated with a water-cooled copper coil of rectangular cross section driven by a $50-\mathrm{kW}, 50-\mathrm{kHz}$ power supply. The coil, shown in Fig. 4, consists of two 3-turn segments connected in parallel and potted in a high-alumina refractory cement ${ }_{r}^{3}$ which serves to prevent arcing between turns of the coil. Foamed zirconia refractory (or porous alumina board, in early castings) placed between the mold and coil serves as a radiative heat shield. The graphite molds are sufficiently thick ( $50 \mathrm{~mm}=2 \mathrm{in}$.) that they couple reasonably

ZYP Coatings, Inc., Oak Ridge TN, Type Y yttria coating. Ipsen Ceramics, Pecatonica, IL, Type ICB-4200 and ICB-4300.

3 AREMCO Products, Inc. Ossining, NY, Ceramacast 510. 
well to the magnetic field. As a result, temperatures of $1000^{\circ} \mathrm{C}$ could be achieved without difficulty. The thinness of the metal mold $(12.7 \mathrm{~mm}=0.5 \mathrm{in}$.), however, limited the temperatures that could be obtained by direct coupling to only a few hundred degrees centigrade. To circumvent this difficulty, titanium plates $19 \mathrm{~mm}(0.75 \mathrm{in}$.) thick and approximately $100 \mathrm{~mm}(4 \mathrm{in}$.) high were attached to the sides of the mold, just under the header bar (see Fig. 1). To provide a complete loop for the induced current, rectangular pieces of tantalum $3.2 \mathrm{~mm}$ $(1 / 8$ in.) thick were used to join these plates at each end. ${ }^{4} \mathrm{~A}$ thin piece of tantalum sheet was placed between the titanium plates and the mold body to prevent diffusion bonding. With this arrangement, satisfactory mold temperatures were achieved.

Prior to heating, the chamber is evacuated first with an oil-free reciprocating pump and then with dual cryopumps. After a preliminary bake-out of the crucible and mold at approximately $1000^{\circ} \mathrm{C}$ and subsequent cooling of the system, the cold vacuum inside the chamber is typically in the low$10^{-6}$ to mid- $10^{-7}$ Torr range $\left(10^{-3}\right.$ to mid $\left.-10^{-4} \mu \mathrm{m}\right)$. At pour time, with the crucible and melt at approximately $1500^{\circ} \mathrm{C}$ and the mold at $800-1200^{\circ} \mathrm{C}$, the vacuum deteriorates significantly because of outgassing, and the pour typically occurs in a vacuum in the mid-10-3 Torr (3- to $6-\mu \mathrm{m})$ range.

The temperature of the crucible is monitored with tantalum-sheathed, type $S$ thermocouples $1.6 \mathrm{~mm}(1 / 16 \mathrm{in}$.) or $3.2 \mathrm{~mm}(1 / 8 \mathrm{in}$.) in diameter placed in the crucible wall, inside the stopper rod, and inside a yttria-coated alumina thermocouple well, which protrudes into the melt itself. The liquid metal typically is poured when its temperature reaches 1500 to $1550^{\circ} \mathrm{C}$, as measured by the thermocouple in the melt. The mold temperatures are monitored with a suite of six, tantalumsheathed, type $S$ thermocouples or Inconelsheathed, type $K$ thermocouples. These thermocouples are placed from top to bottom on the center line of the mold and along one side. The measured temperatures at the top of the mold ranged from 1000 to $1200^{\circ} \mathrm{C}$ and at the bottom from 800 to $950^{\circ} \mathrm{C}$. All thermocouple measurements, as well as other selected foundry data, are captured and recorded digitally using a Macintosh computer running LabView software.

\section{Casting Results}

The first casting of uranium- $6 \mathrm{wt} \%$ niobium $(3.2 \mathrm{~kg})$ served only to check foundry systems and to verify that the mold could contain the melt without leaks. Table 1 summarizes conditions for the remaining four castings. All of the castings were in the range of 6 to $6.2 \mathrm{~kg}$ with the exception of U6-03, which used a smaller, "half-size" mold to vary the casting conditions for subsequent comparisons to numerical simulations. Figure 5 shows a photograph of U6-02.

Figure 6 shows the top-, middle-, and bottomcenter mold temperatures for casting U6-06. The slight rise in temperature immediately after the liquid metal fills the mold and the subsequent montonic decrease in temperature are typical of all the castings prepared in yttria-coated graphite

Table 1. Summary of U-6 wt $\% \mathrm{Nb}$ flat-plate casting experiments.

\begin{tabular}{lcccc}
\hline & U6-02 & U6-03 & U6-06 & U6-07 \\
\hline Charge mass (kg) & 6.2 & 4.5 & 6.1 & 6.0 \\
Mold material & Graphite & Graphite & Graphite & Ta-10wt\%W \\
Melt temperature $\left({ }^{\circ} \mathrm{C}\right)$ & 1530 & $1428^{\mathrm{a}}$ & $1658^{\mathrm{a}}$ & 1543 \\
Coil type & Unpotted & Potted & Potted & Potted \\
Mold temperature at pour $\left({ }^{\circ} \mathrm{C}\right)$ & $940-1072$ & $900-1200$ & $950-1150$ & $800-1060$ \\
Refractory type & Alumina board & Alumina board & Foamed zirconia Foamed zirconia \\
Thermocouples & $1.6 \mathrm{~mm}$, type S & $1.6 \mathrm{~mm}$, type S & $3.2 \mathrm{~mm}$, type K & 1.6 mm, type S \\
\hline
\end{tabular}

\footnotetext{
${ }^{a}$ Questionable measurements.
}

4 The end plates were intended to minimize the current that flows through the bolts that hold the mold, with the titanium susceptors, together. A thickness of $3.2 \mathrm{~mm}$ was deemed to be sufficient, because the skin depth is only $1.6 \mathrm{~mm}$ in tantalum and $3.3 \mathrm{~mm}$ in titanium at a frequency of $50 \mathrm{kHz}$. 
molds. Comparison of the cooling curves in Fig. 7 and the slopes of these curves in Fig. 8 shows that differences in the moderate initial cooling rates $\left(0.5^{\circ} \mathrm{C} / \mathrm{s}\right)$ lead to detectable differences in the later time thermal histories.

Figure 9 shows the microstructure of casting U6-02. The top of the casting, near and in the header bar, contains some shrinkage porosity, as expected (see Fig. 9[a]). The matrix material consists of a mixture of a featureless phase surrounded by what appear to be regions that have phaseseparated on a fine scale. The porosity and the amount of the featureless phase decrease steadily down the casting until only the finely divided, phase-separated material remains at the bottom (see Fig. 9[c]). Casting U6-03, which cooled somewhat more rapidly than $\mathrm{U} 6-02$, has what appears to be a considerably different microstructure, as shown in Fig. 10. Shrinkage porosity is visible throughout the casting, but is concentrated near the external surfaces. In contrast to U6-02, featureless material dominates the microstructure throughout U6-03, and a second phase appears only at pores, grain boundaries, inclusions, and other lattice defects. The microstructure of U6-06 (see Fig. 11) is much the same as U6-03, but the second phase regions are somewhat smaller. $\mathrm{X}$-ray dispersive chemical analysis and microprobe characterization reveal no obvious segregation of $\mathrm{Nb}$ or $\mathrm{U}$ in any of the features noted in optical micrographs, although some inclusions contain substantial amounts of $\mathrm{Nb}$ and are probably carbides. Examination of the time-temperature-transformation diagram for $\mathrm{U}-6 \mathrm{Nb}^{5}$ with the cooling curves for the middlecenter of the castings superimposed (Fig. 12) suggests that the final microstructures should consist of a matrix of a martensitic $\alpha^{\prime \prime}$, which contains some phase-separated regions of intimately mixed $\alpha$-and $\gamma$-like material). Hence, one interpretation of the as-cast microstructures is that the featureless material is $\alpha^{\prime \prime}$ with the $\mathrm{Nb}$ still in solution within which some $\alpha$ and $\gamma$ has begun to nucleate and grow at lattice imperfections. The more slowly the casting cooled, the greater the extent of transformation and growth of the $\alpha$ and $\gamma$ material. However, it is not clear from this interpretation why the bottom of U6-02, which cooled more rapidly than the top, should be completely transformed and phase-separated to $\alpha$ and $\gamma$, if these are indeed the phases present.

The metal mold and the casting prepared in it, U6-07, are shown in Fig. 13. The casting released easily from the mold, and the surface quality appeared to be good. However, several depressions, readily visible on one side of the casting, indicate substantial lateral shrinkage during solidification and are probably associated with internal shrinkage porosity. Thermocouple measurements (see Fig. 14) show that the middle center was the hottest portion of the mold at the time of the pour and that the header bar was relatively cool $\left(880^{\circ} \mathrm{C}\right)$. Hence, it seems likely that a pool of liquid metal in the middle center was the last to solidify. To produce a sound casting, the header must be at least as hot as the hottest part of the mold, and preferably it should be hotter so that liquid metal retained in the header is available to fill voids created as material below solidifies. The reason the header was so cool in this case was simply that the header, while considerably thicker than the body of the mold, was not as thick as the titanium susceptor assembly. As a result, the header, which was not surrounded by the susceptor, coupled directly but less efficiently to the magnetic field and therefore remained cooler than the middle portion of the mold. This situation can easily be mitigated in future experiments by extending the susceptor up around the header. 6

The mold showed no apparent ill effects from the casting and appears to be reusable. A slight spring-back of the mold halves when the bolts were removed during disassembly may indicate minor warping, but this had no effect on the casting and did not appear to be large enough to cause any reassembly problems. There was no evidence of any attack by liquid uranium, although the time available prior to solidification is short (on the order of minutes). The plasma-sprayed yttria coating remained intact and adherent over much of the mold cavity surface after removal of the casting. In those sections where it remained, it could not easily be removed with a scraping tool. However, the coating was lost in several areas where erosive effects are severe, most notably in regions such as the sides below the entry opening and at the bottom, where the entering stream of liquid metal

\footnotetext{
5 Rocky Flats Technical Datasheet Number RFP-1613, “Uranium-6\% Niobium,” Figure F6-a, January 1971.

6 To ensure that the header is hotter than the mold body, it might be advantageous to increase the susceptor width around the header so that coupling there is more efficient.
} 
strikes the mold. Interestingly, in a few regions, dribbles of yttria slurry that were accidentally dropped while sealing the mold parting line remained intact and impressed their contour onto the casting. Hence, a light wash of yttria slurry applied over the plasma-sprayed coating might prevent any adherence to the casting and thereby preserve the plasma-sprayed coating for reuse. The amount of flashing at the parting line was minimal, indicating that any gaps were successfully sealed with yttria slurry.

The cooling curve for the middle-center thermocouple of U6-07 has a "knee" approximately $450 \mathrm{~s}$ after the pour, which appears as a distinctive reversal in the slope (see Figs. 8 and 14). Although it is not readily visible, analysis of the slopes shows that this feature is also present at approximately the same time in all the curves. The shape of the knee is consistent with its being caused by the latent heat of fusion as the liquid solidified. It is detectable in the metal mold because the thermocouples were placed much closer to the melt than in the graphite molds, where they were at the outer surfaces, somewhat less than an $25 \mathrm{~mm}$ from the melt. However, the frequency of data acquisition was changed shortly after the knee, and the effects of this change on the shape on the cooling curve have not been established.

\section{Summary}

Our results show that refractory metal molds of tantalum-based alloys can be used with conventional yttria protective coatings in the casting of $\mathrm{U}-6 \mathrm{Nb}$. Plasma-sprayed yttria adhered well to the Ta-10W and protected it from attack during the brief period before the liquid uranium solidified. Warping of the mold did not appear to be a serious problem, even with a pour temperature as high as $1543^{\circ} \mathrm{C}$. The casting was easily extracted from the mold and left much of the yttria coating intact on the surfaces of the mold cavity.

\section{Modeling Near-Net Shape Casting of Uranium-6\% Niobium Alloys (P. Raboin)}

As a part of the modeling objective for nearnet shape casting of $U-6 \mathrm{Nb}$ alloys, thermofluid finite element analyses were performed to simulate and predict the mold-filling characteristics, solidification behavior, and cooling rates of $\mathrm{U}-6 \mathrm{Nb}$ flat plates. All calculations were made with the commercial casting software package called ProCAST. ${ }^{7}$ This code is capable of predicting the free-surface flow of molten metal into a die cavity and of modeling the heat transfer and solidification phase change occurring during cooldown.

Analytical efforts were focused primarily on predicting the mold behavior of flat-plate geometries. Four geometries were considered. The first two were early design options for graphite and tantalum molds (never constructed) that had a thin plate thickness $(0.125 \mathrm{in}$.). The third was the graphite mold of Fig. 2, and the fourth was the half-size mold described in the previous section. Analyses were performed using $\mathrm{U}-6 \mathrm{Nb}$ and $\mathrm{Cu}$ melt materi- als. These calculations were intended to give information on mold design, predict cold shutting, and determine a range of acceptable casting process conditions. In this section, we will describe flatplate mold filling and show three examples of how these calculations added confidence to this research project.

Another very useful casting modeling tool developed during this SERDP work is simulation videos of die filling. Two mold-filling animations were constructed using ProCAST simulation data. In this section, still pictures taken from some of the early graphite mold work are described. A complete mold filling, solidification, and cooldown analysis was performed to compare analysis with thermocouple results. These calculations were very time-consuming, because ProCAST takes two weeks per simulation. This section summarizes the important heat-transfer lessons learned and makes recommendations for future calculations.

7 D. M. Waite, and M. T. Samonds, "Finite Element Free Surface Modeling," in Modeling of Casting, Welding and Advanced Solidification Processes-VI, Conf. Proc. (The Minerals, Metals \& Materials Society, 1993). 


\section{Flat-Plate Mold Filling Analytical Results}

In this section, the basic characteristics of flatplate mold filling are described first. Space and time restrictions do not allow a complete description of the entire record of analytical results, so three case studies will be described. The first example shows how analytical results were used to modify the flat-plate mold design. The second case describes an investigation into the effect of a tantalum funnel on the course, direction, and temperature of the molten metal flow. The last case is a cold-shut calculation to find a lower-bound mold temperature. (A cold-shut is a premature solidification of liquid metal, which causes casting defects or flow diversions that adversely affect the casting quality.) The two die-filling videos created during this work should be viewed as a part of this report; interested parties should contact the authors for further information.

The first two mold-filling calculations were performed to characterize and compare the diefilling behavior of graphite and tantalum flat-plate molds (Figs. 15-18 and 19-20, respectively). These results were representative of most of the filling cases studied. The finite-element models use a $1 / 4$-symmetry representation. The initial temperature conditions are determined with a preliminary heat-transfer analysis in which a direct heat flux is applied to the upper sides of the mold (position of inductive heaters) and radiant heat losses are specified on all exterior die surfaces. The heat input and radiant output are adjusted to match thermocouple temperatures measured on the mold surface. The metal enters the mold cavity at $1500^{\circ} \mathrm{C}$ with a velocity determined from crucible flow calculations. In most cases, a very high heattransfer coefficient $\left(20,000 \mathrm{~W} / \mathrm{m}^{2}\right)$ is assumed for the casting-mold interface. This results in higher than expected heat-transfer rates, but using a high heat-transfer coefficient should result in conservative predictions of cold-shuts.

The mold-filling sequence typically has four distinct phases. In the first phase, the metal enters the header region and begins to flow down into the flat-plate space (Fig. 15). The second phase has the metal filling the flat plate (Fig. 16). The third concerns the flow cutoff and the sloshing of liquid in the header (Fig. 17). The last phase involves natural convection flows and a drop in the fluid level as the solidification phase transformation changes the casting density and metal from the header feeds the flat-plate casting (Fig. 18). The mold-filling results reported in this section deal mainly with the first three phases.

The crucible opening diameter and the plate thickness have the greatest influence on the transverse flow of metal across the header. With a small crucible diameter and a large plate thickness, the metal flows directly down into the flat plate, largely unaffected by the header geometry. Conversely, a large crucible diameter and a small plate thickness causes a large transverse flow and may cause backing up of metal and mold overflow. Ideally, there would be mostly transverse flow and no flow backup. In all of the cases modeled thus far, the first phase had mostly a downward flow with very little transverse flow. The final mold design has the greatest amount of transverse flow.

The second phase of mold filling depends strongly on the first phase, but in all cases studied the flow is circular. The metal comes down the plate center to the mold bottom, flows outward to the exterior walls, and then, depending on the plate geometry, flows up the wall. For the larger plates, the flow momentum at the outer vertical plate wall was insufficient to carry the flow up to the header region, so the flow would fall back toward the plate center. In the half-size mold, the metal shot all the way up and caused a backfilling of the header. In all of these cases, there was a steady flow of metal across the mold bottom and sides, which caused local wall heating. The circular flow behavior also mixes colder circulating liquid with hotter melt material fresh from the crucible. A final feature of this phase is that the initial flow down to the mold bottom occurs in a jetting mode. From video prediction results, it was learned that the plate acts as a flow constrictor from the header, and this causes a flow separation of the melt from the mold surface. The plate thickness and flow velocity have the greatest influence on this behavior. Because of the unstable nature of this kind of flow, the perfect symmetry inherent in these simulations is probably unrealistic. Thus, the simulation is underestimating the heat transfer between the melt and mold wall during the initial drop of metal to the mold bottom.

The third phase of mold filling seems to have no effect on the quality of the plate casting. As the second phase finishes, a final flow of material wells up from the flat plate and fills the header. In all of the simulations, this causes a local heating of the header, but it has no long-term consequences. Once the plate is full, the flow diverts and fills the header very quickly. When the crucible flow stops, and the last of the metal enters the header, a small surface 
depression is observed in the center of the header. A small rebounding jet occurs (several inches high), and the liquid sloshes around. The header liquid is hotter than the liquid in the plate section.

The last phase, natural convection and solidification shrinkage, is critical to the overall solidification process, but the convective flows and shrinkage behaviors did not vary significantly in any of the simulations. These processes are strongly governed by the temperature fields and thermal processes. The convective flows are all very small (velocities $<10^{-4} \mathrm{~m} / \mathrm{s}$ ), because temperature gradients within the melt are also small. The large temperature gradient exists in the mold, not the melt. Similarly, during solidification, the casting gradients decrease even further, while mold gradients also decrease. After solidification, there is no significant difference between the casting and mold temperature gradients. Solidification starts first at all of the mold walls but then develops into a directional solidification in which the plate bottom hardens first and the header last. The analysis predicts a drop in the header fluid level during solidification.

The final flat-plate mold design has a modification not detailed in Fig. 2. This modification (Fig. 21) was the solution to a small flow prediction problem (seen in video) that indicted an impinged metal flow into the header. The impingement occurs at the mold edge between the vertical inflow opening and the horizontal header top. This $90^{\circ} \mathrm{C}$ corner in the flow cavity is replaced with a large $45^{\circ} \mathrm{C}$ beveled edge. A subsequent analysis shows no impingement to the header flow. This minor modification is the first example of how design analysis can make small improvements to improve a mold design.

The second example was an analysis of the thermal and fluid effects of a tantalum funnel used at the opening to the graphite crucible (Fig. 21). Up to this time, the crucible opening had been assumed to be smaller than the mold opening. However, the minimum dimension of the rectangular opening to the mold was actually less than the crucible diameter. Further complicating this fact was the difficulty in heating the funnel to the same temperature as the mold. There were, therefore, concerns about the effect this funnel would have on the flow behavior and on the cooldown in the melt temperature.

With the finite element model of the funnel and mold, and with all the associated heat-transfer behaviors modeled, the analysis predicted no significant effects on the melt behavior. In fact, the flow of metal to the header was probably improved, because the inlet stream is modified from circular to rectangular prior to reaching the header, and the flow volume is higher, improving the header fill rate. The fill time $(0.3 \mathrm{~s})$ is shorter because of the higher fill rate and the temperature loss in the melt is relatively minor (less than $10^{\circ} \mathrm{C}$ when the melt first reaches the mold bottom). The funnel is made of tantalum sheet, so it quickly heated to the melt temperature. In short, the flow is too quick for significant heat losses, and the funnel has insufficient thermal mass to significantly cool the melt. This analysis eliminated the funnel as a possible design problem and added confidence to the overall system design.

The last case for the importance of moldfilling analysis concerns its use in predicting coldshuts. The procedure employed here is to run a series of analyses in which the mold temperature is reduced until a cold-shut is observed. The flat-plate design model had a cold-shut temperature that varied most with plate thickness, keeping the pour temperature and heat-transfer rate constant. For the 1/4-in.-thick plates, the mold cold-shut temperature was between 700 and $800^{\circ} \mathrm{C}$, and for the 1/8-in.-thick plates, the cold-shut temperature was between 900 and $1000^{\circ} \mathrm{C}$. The $\mathrm{U}-6 \mathrm{Nb}$ liquidus to solidus temperature range is 1320 and $1220^{\circ} \mathrm{C}$, respectively. Thus, the $1 / 4$-in. mold temperature is $500^{\circ} \mathrm{C}$ lower than the liquidus temperature. The $100^{\circ} \mathrm{C}$ uncertainty in the cold-shut temperature arises from the fact that at the higher temperatures, solidification begins but the flow of hot metal causes a remelting and heating of the mold surface. At the lower cold-shut temperature, there is significantly more solidification, although in every case modeled, the partially solidified material remelts. This situation requires a judgment call, since in reality, the flow may pick up the solidified nuclei and transport it or these small nucleated particles might alter the flow path. In any case, the presence of significant solidification on the mold walls was judged to be significant evidence of cold-shutting.

The cold-shut criteria became important during the operation of the furnace when acceptable ranges for casting conditions were needed. On the first and second $\mathrm{U}-6 \mathrm{Nb}$ castings, the unpotted mold heater had some difficulties raising the mold temperature above $1000^{\circ} \mathrm{C}$. Thus, it was necessary to know the minimum mold temperature for a successful casting operation. This analysis was put to the test just once (U6-02), when during a holding period of the crucible melt at $1500^{\circ} \mathrm{C}$, the mold heaters failed. As the mold temperatures decreased 
(by about $150^{\circ} \mathrm{C}$; the minimum indicated temperature on the mold was about $850^{\circ} \mathrm{C}$ ), it was decided to go ahead with the pour. The pour resulted in one of the better castings. Thus the experiment benchmarked the analytical process parameter of mold pour temperature, and it confirmed the practical casting rule of thumb that higher cooling rates,improve casting quality.

\section{Flat-Plate Solidification and Cooldown Analytical Results}

The U6-02 experiment was selected for more detailed analysis to benchmark the analytical predictions with some experimental results. The goal was to simulate the entire casting process and then use the analytical results to obtain solidification information (cooling rates, gradients, and solidification velocities) at various locations within the casting product. The first analysis task was to model the heatup and steady-state thermal conditions. The second task was to model the cooldown. (This experiment was the one in which the mold heater failed and the pour was started several minutes after the failure.) Results from both analyses were then combined to match and compare with thermocouple measurements. During the experiment, six thermocouples at the mold center and outer edge were located at the top, middle, and bottom of the molds. Finally, cooling and solidification information was processed from the analytical results.

Figure 22 shows the six locations at which analytical predictions are made. Figure 23 shows the pattern of heating boundary conditions used to model this problem. Figure 23 includes a table showing the steady-state heat fluxes used during the mold heating. During the pour and cooldown, the input heat fluxes are zeroed and only the radiant heat loss terms remain. Figure 24 shows a steady-state prediction of the mold heating and the corresponding experimental results. All of the predicted temperatures are within $30^{\circ} \mathrm{C}$ of the measured values (see Fig. 21). Along the plate center, the temperature gradient is higher than expected in the vertical direction, while at the plate edge it is lower. Horizontally, the temperature gradient is correct for the top but is lower for the middle and bottom. It took seven iterations of modifying heating-boundary conditions to match these results.
Figure 25 shows ProCAST and experimental results for the case in which the mold is heated and then cooled with no metal pour into the mold. This calculations and comparisons were performed to verify that without the thermal mass of the casting in the mold, the mold assembly cools faster than in the experimental run with a casting in the mold. As the plot demonstrates, the ProCAST cooling rate exceeds that in the experiment. For most of the cooldown, the predicted temperatures are $150^{\circ} \mathrm{C}$ lower than the measured values.

Figures 26 and 27 show ProCAST and experimental results for a casting in the mold. Two shortcomings are immediately observed. First is the error associated with the start time for the pour of metal into the mold. An allowance for the initial time delay offset at the experiment beginning was unintentionally omitted, so the predicted pour occurs $504 \mathrm{~s}$ too late. The error was not detected until after the analysis completion. Repeating the analysis will not significantly change the results, so a second run was not performed.

The second, and more significant, shortcoming is the lower-than-desired cooling rates observed in the results. The casting and mold do not cool at nearly the same rate. Five hours after the pour, the predicted temperatures are almost $200^{\circ} \mathrm{C}$ higher than the measured values. The differing cooling rate is immediately evident and causes the predicted and experimental temperature differences to steadily widen with time. The effects of the latent heat of liquid-solid phase transformation are evident in the predicted response but are absent from the experimental measurements.

Three areas of uncertainty make this cooldown prediction risky. First is the errors associated with simplifying the complex foundry heat-transfer conditions to a practical analytical model. Second is the uncertainty of material properties for the mold and casting. Third is the evolving heat-transfer properties across the mold-part interface. Of these three areas, the exterior heat balance is the most serious. This section discusses the analytical methodology and makes suggestions to improve the analytical method.

The mold was surrounded by several insulating sheets of aluminum oxide and an unpotted inductive heater. Analytical predictions of the casting process had assumed idealized heattransfer boundary conditions surrounding the mold, and these were only qualitatively similar. As shown in Fig. 23, the energy of the inductive 
heaters is modeled as a surface heat flux to the mold. The problem here is not the flux model as such, but the fact that there is no spatial distribution of heat flux. We do not have a model to predict the inductive coupling between the inductive coils and the molds. Thus, the magnitude and distribution of heat into the mold system is unknown. In practice, the initial mold-temperature distributions and thermal configuration are far more complex than those in the model. Thermocouple measurements on the mold exterior showed a larger temperature gradient from center to edge than could be predicted from heat loss effects alone. Because of limitations of time and resources, threedimensional enclosure radiation calculations were not performed, so exact heat-transfer exchange coefficients were not determined. Thus, the idealized heat transfer boundary conditions chosen in this analysis are probably inadequate, but finding better ones is an uncertain trial-and-error process.

The second set of errors concerns the uncertainty of heat transfer properties. Tables 2 through 5 list the properties used in these analyses. These values were obtained from published reports and were not experimentally verified as input to the model. A higher-than-expected thermal mass might explain the lower cooling rate, but the casting density and heat capacity have reasonable values $\left(16 \mathrm{gm} \cdot \mathrm{cm}^{-3}\right.$ and $0.025 \mathrm{cal} \cdot \mathrm{g}^{-1} \cdot{ }^{\circ} \mathrm{C}^{-1}$, respectively).

The third area of uncertainty concerns the evolving heat-transfer properties at the mold-part interface. The interface coefficient varies both in time and space because of material phases, temperatures, pressures, gap distances, and surface qualities. Chronologically, the interface is initially liquid-solid, then pressure-dependent solid-solid, and then (as gaps open) the interface is dominated by thermal radiation, a function of emissivityabsorptivity and the fourth power of surface temperature. Modeling these processes is beyond the capability of ProCAST, so a liberally high heattransfer coefficient of $20 \mathrm{~kW} / \mathrm{m}^{2}$ is assumed throughout the analysis. This value applies best to the condition of liquid-solid or high-pressure solid-solid interfaces. Thus, the analytical predictions of cooldown occur more rapidly than they should, especially in the latter stages when the interface temperatures have dropped and large gaps have formed $\left(200 \mathrm{~W} / \mathrm{m}^{2}\right.$ is more likely).

Qualitatively, these calculations were successful, but quantitatively the analytical results are inadequate. They require more careful and detailed material, geometric, and thermal information to improve the prediction accuracy. Several simple mistakes were made during the analysis process, and more important, errors in the methodology were identified and can be corrected for the next benchmarking attempt. Next time, an experimental simulation of mold heatup and cooldown without the casting pour would be useful. This will provide radiation-only, heat-transfer data needed for deriving idealized heat-transfer boundary conditions. This is also important because it separates the heat-transfer boundary condition effects from uncertainties associated with casting heat transfer material properties and casting-mold interface heat-transfer properties.

Finally, thermal solidification information is contained in Tables 6 and 7 for the predicted casting. Data are reported here for the locations that line up on the plate mid-surface and on the plate center. (See Fig. 22). The cooling rate $L$, the temperature gradient $G$, the solidification velocity $R$, and a combined $G / R$ ratio are given for each data location. The data set is predicted at two temperatures: $1220^{\circ} \mathrm{C}$, the liquidus temperature, and $600^{\circ} \mathrm{C}$, a temperature at which other researchers ${ }^{8}$ have made observations. A $G / R$ of greater than 1.8 is recommended for good-quality casting. ${ }^{9}$ Because the predicted cooling rates are known to be too low, this solidification information will also be too low.

\section{Summary}

In conclusion, thermofluid finite-element analyses were used to study the mold-filling characteristics, solidification behavior, and cooling rates of $U-6 \mathrm{Nb}$ flat plates. The ProCAST simulation code successfully calculated mold filling and predicted cooldown. Comparisons of predictions with measurements reveal lower cooling rates than expected. An examination of cooldown simulation assumptions indicates that additional characterizations of thermal boundary conditions are needed to improve cooldown predictions.

8 K. H. Eckelmeyer, A. D. Romig, and L. J. Weirick, "The Effect of Quench Rate on the Microstructure, Mechanical Properties, and Corrosion Behavior of U-6 Wt Pct Nb," Metall. Trans. A 15a, 1319-1330 (1984).

9 C. Bonnet and J. M. Moray, "L'Uranium Et Ses Alliages," Chocs. 6, 67-80 (1992). 
Table 2. U6-6Nb density.

\begin{tabular}{cc}
\hline Temperature $\left({ }^{\circ} \mathrm{C}\right)$ & Density $\left(\mathrm{g} / \mathrm{cm}^{3}\right)$ \\
\hline 25 & 17.47 \\
1220 & 16.01 \\
1320 & 15.50 \\
1623 & 15.10 \\
\hline
\end{tabular}

Table 4. U-6Nb thermal conductivity.

\begin{tabular}{cc}
\hline Temperature $\left({ }^{\circ} \mathrm{C}\right)$ & $\begin{array}{c}\text { Conductivity } \\
\left(\mathrm{cal} \cdot \mathrm{cm}^{-1} \cdot \mathrm{g}^{-1} \cdot{ }^{\circ} \mathrm{C}^{-1} \text { ) }\right.\end{array}$ \\
\hline 0 & 0.04 \\
100 & 0.04 \\
400 & 0.07 \\
800 & 0.12 \\
2000 & 0.12 \\
\hline
\end{tabular}

Table 3. U-6Nb heat capacity. ${ }^{\mathrm{a}}$

\begin{tabular}{cc}
\hline Temperature $\left({ }^{\circ} \mathrm{C}\right)$ & $\begin{array}{c}\text { Heat capacity } \\
\left(\mathrm{cal} \cdot \mathrm{g}^{-1} \cdot{ }^{\circ} \mathrm{C}^{-1}\right)\end{array}$ \\
\hline-100.0 & 0.025 \\
600.0 & 0.050 \\
1217.5 & 0.050 \\
1222.5 & 0.285 \\
1317.5 & 0.285 \\
1322.5 & 0.05 \\
2000.0 & 0.05 \\
\hline
\end{tabular}

${ }^{a}$ Heat capacity includes integrated latent heat of solidification.

Table 5. Miscellaneous U-6Nb thermofluid properties.

\begin{tabular}{lc}
\hline Property & Value \\
\hline Solidus temperature & $1220.0^{\circ} \mathrm{C}$ \\
Liquidus temperature & $1320.0^{\circ} \mathrm{C}$ \\
Solidification latent heat & $23.5 \mathrm{cal} / \mathrm{g}$ \\
Viscosity & $0.0065 \mathrm{~Pa} \cdot \mathrm{s}$ \\
\hline
\end{tabular}

Table 6. Solidification information at $1220^{\circ} \mathrm{C}$.

\begin{tabular}{lccc}
\hline & Plate top & Plate middle & Plate bottom \\
\hline Cooling rate $\mathrm{L}_{1320-1220 \mathrm{C}}\left({ }^{\circ} \mathrm{C} / \mathrm{s}\right)$ & 3.08 & 5.29 & 5.53 \\
Cooling gradient $\mathrm{G}\left({ }^{\circ} \mathrm{C} / \mathrm{m}\right)$ & $15.8 \times 10^{3}$ & $0.84 \times 10^{3}$ & $0.66 \times 10^{3}$ \\
Solidification velocity $\mathrm{R}(\mathrm{m} / \mathrm{s})$ & $1.36 \times 10^{-3}$ & $9.34 \times 10^{-3}$ & $2.78 \times 10^{-3}$ \\
$\mathrm{G} / \mathrm{R}\left({ }^{\circ} \mathrm{C}\right.$ min $\left./ \mathrm{cm}^{2}\right)$ & 19.4 & 0.15 & 0.39 \\
\hline
\end{tabular}

Table 7. Solidification information at $600^{\circ} \mathrm{C}$.

\begin{tabular}{lccc}
\hline & Plate top & Plate middle & Plate bottom \\
\hline Cooling rate $\mathrm{L}_{1320-1220 \mathrm{C}}\left({ }^{\circ} \mathrm{C} / \mathrm{s}\right)$ & $0.555 \times 10^{-3}$ & $0.541 \times 10^{-3}$ & $0.526 \times 10^{-3}$ \\
Cooling gradient $\mathrm{G}\left({ }^{\circ} \mathrm{C} / \mathrm{m}\right)$ & $0.156 \times 10^{3}$ & $0.087 \times 10^{3}$ & $0.279 \times 10^{3}$ \\
Solidification velocity $\mathrm{R}(\mathrm{m} / \mathrm{s})$ & $0.269 \times 10^{-3}$ & $0.466 \times 10^{-3}$ & $0.157 \times 10^{-3}$ \\
\hline
\end{tabular}



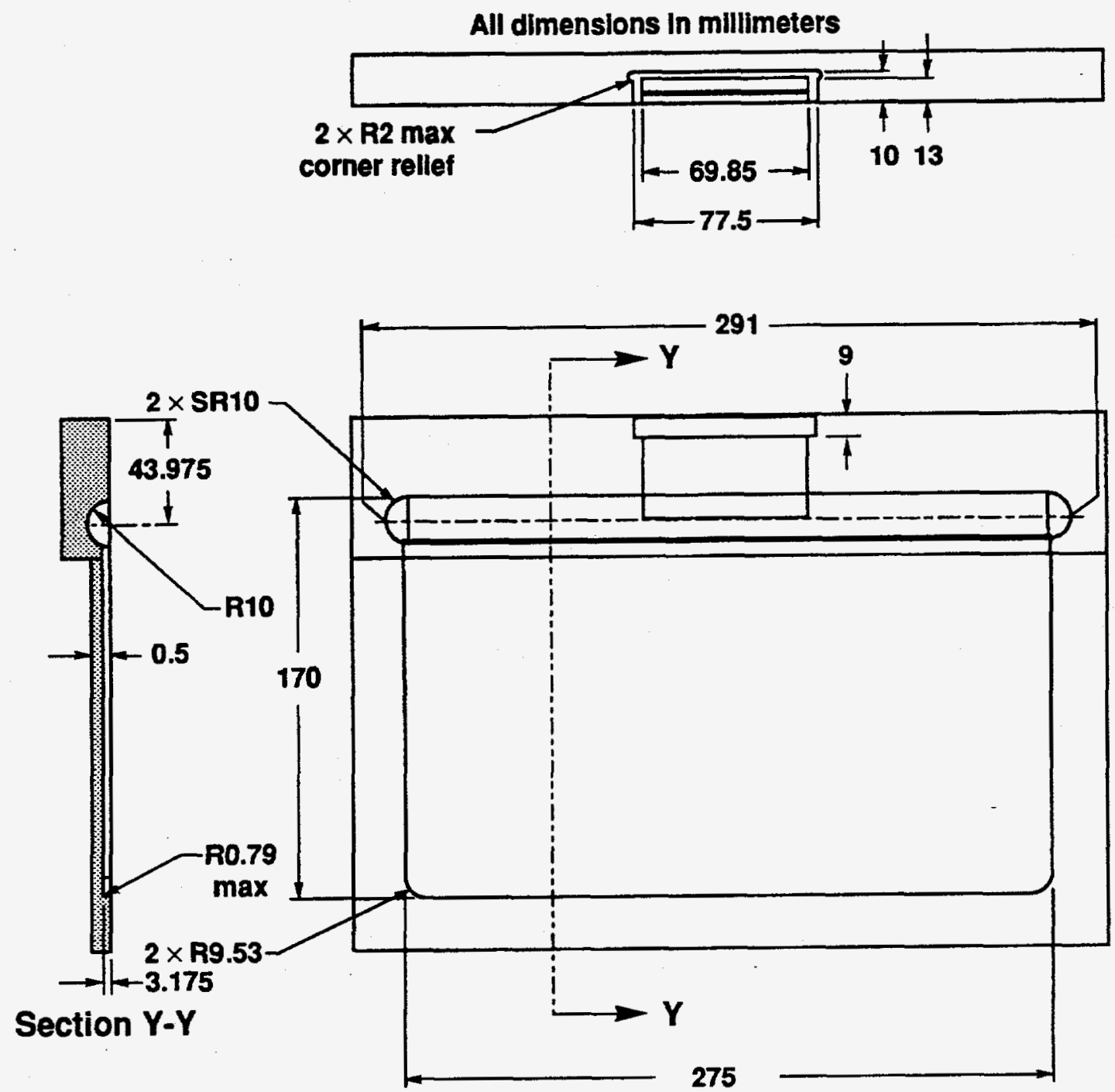

Figure 1. Drawing of the flat-plate mold fabricated from tantalum-10wt \% tungsten alloy. 
All dimensions in millimeters
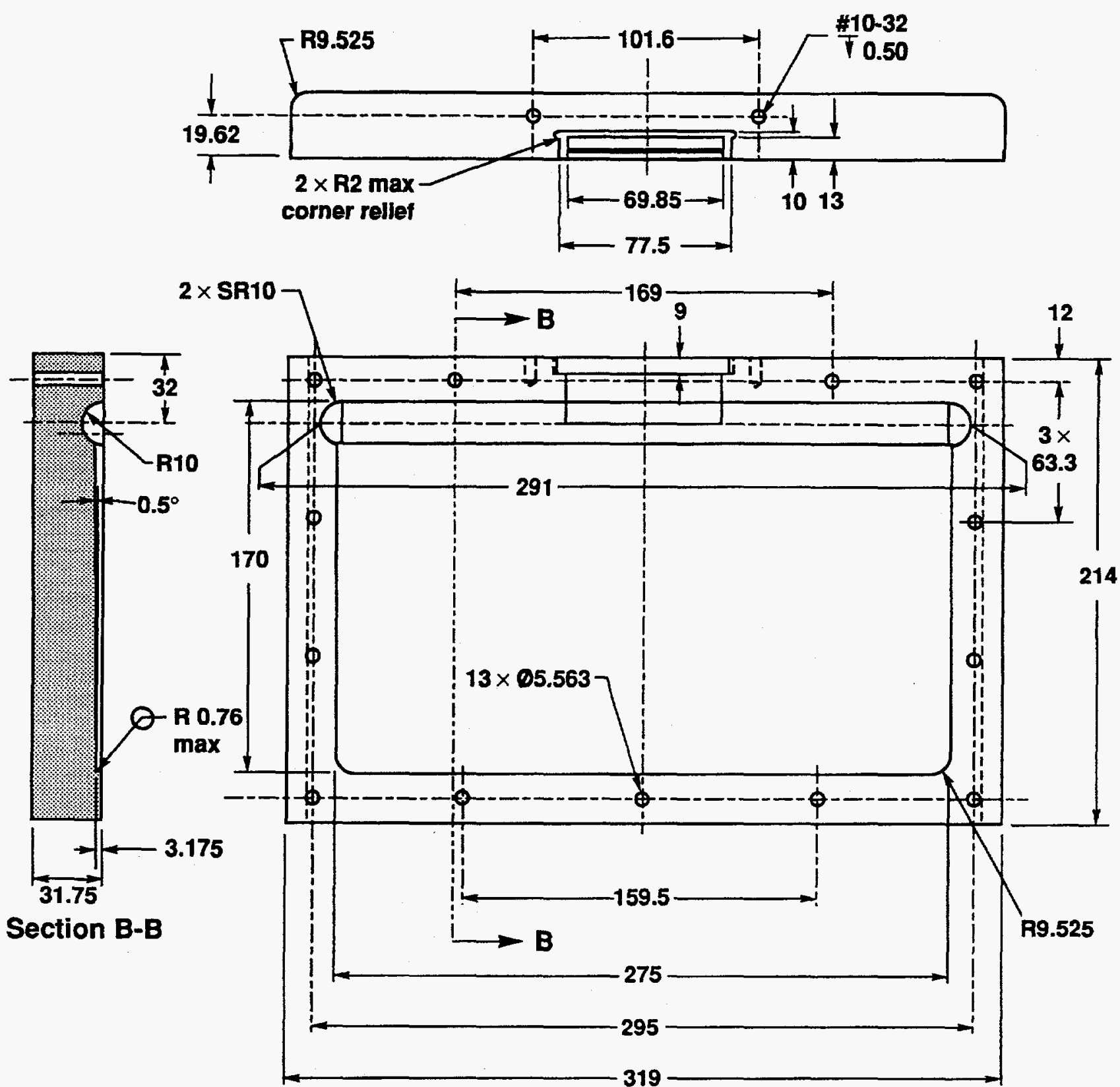

Figure 2. Drawing of the flat-plate graphite mold. 


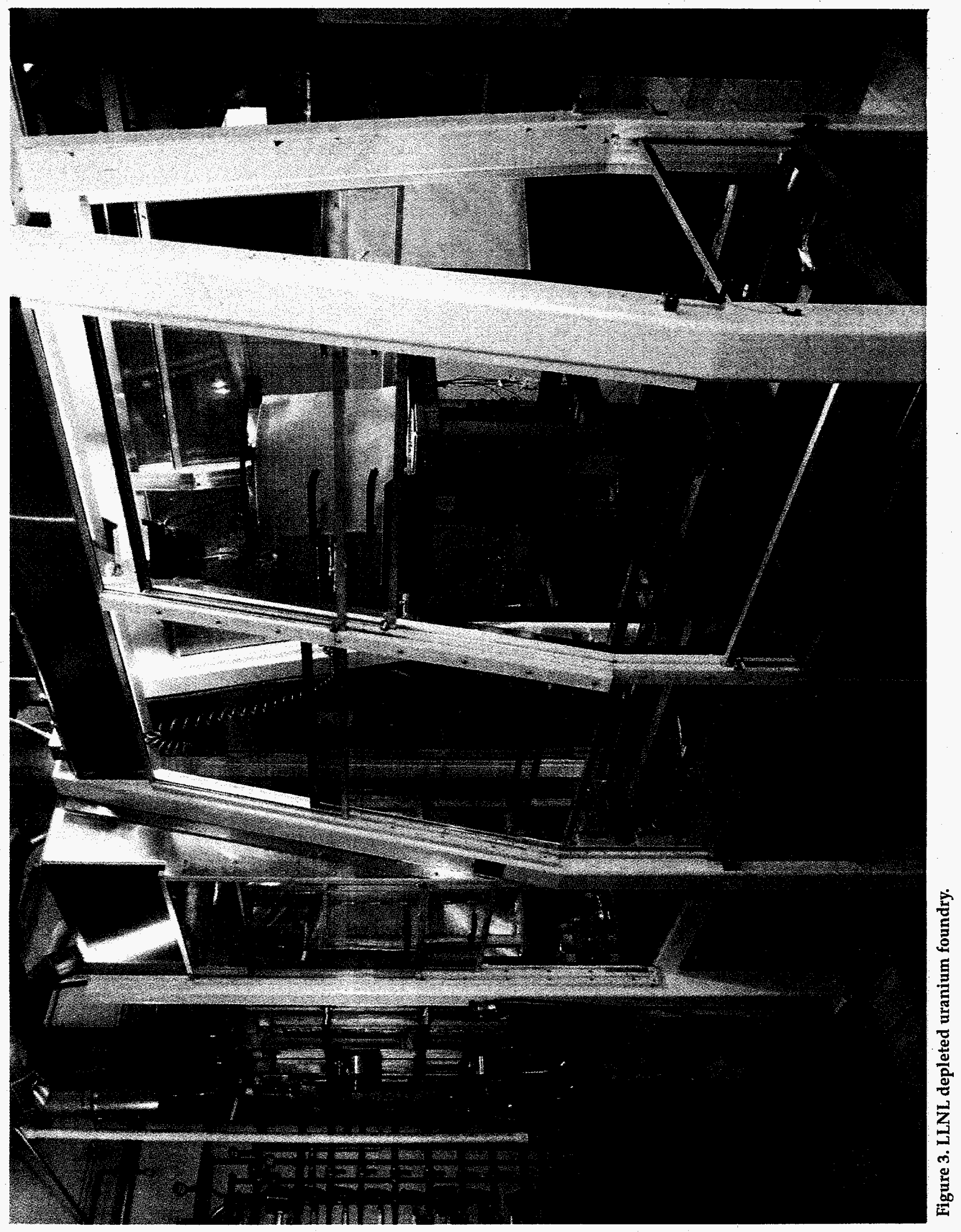




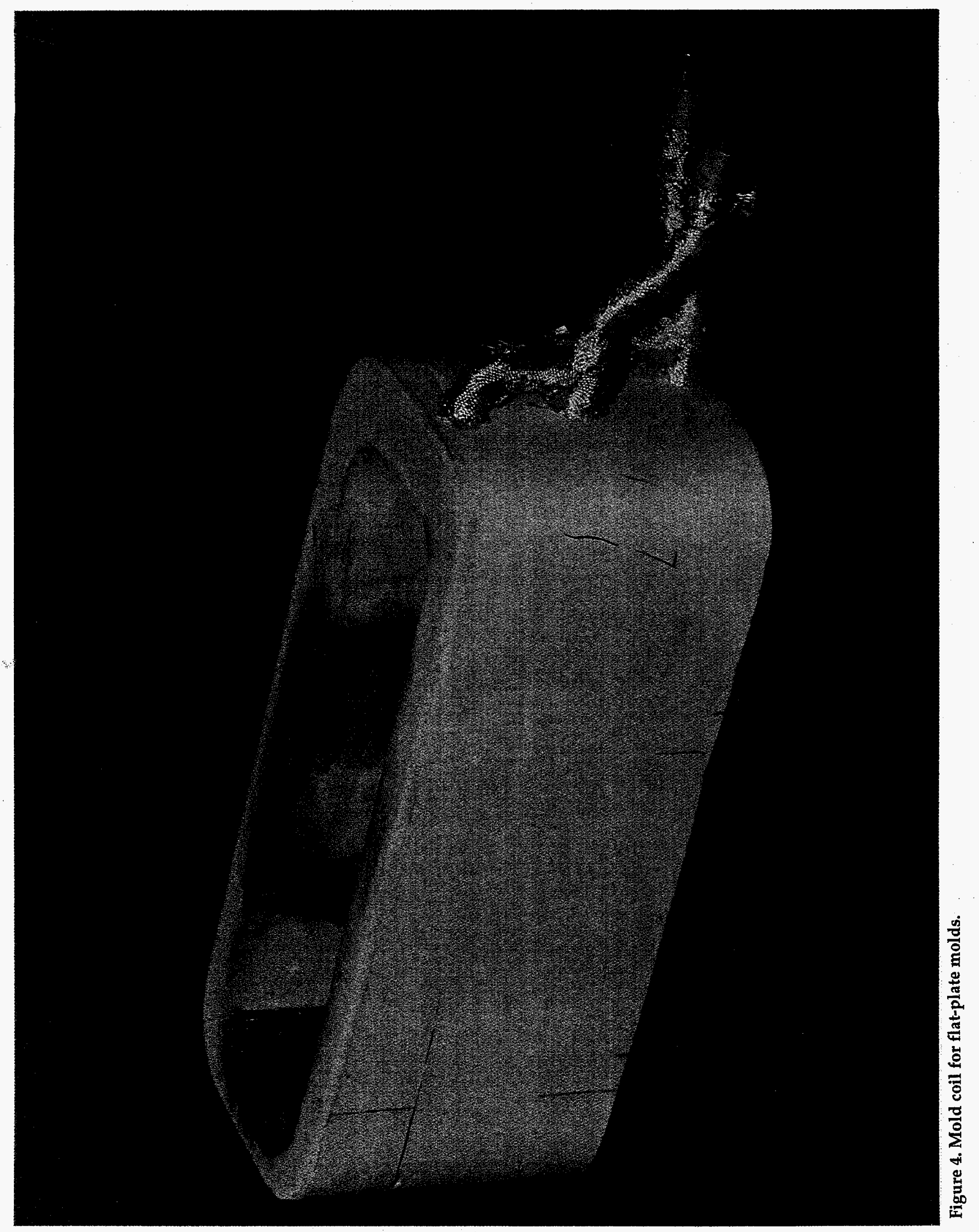




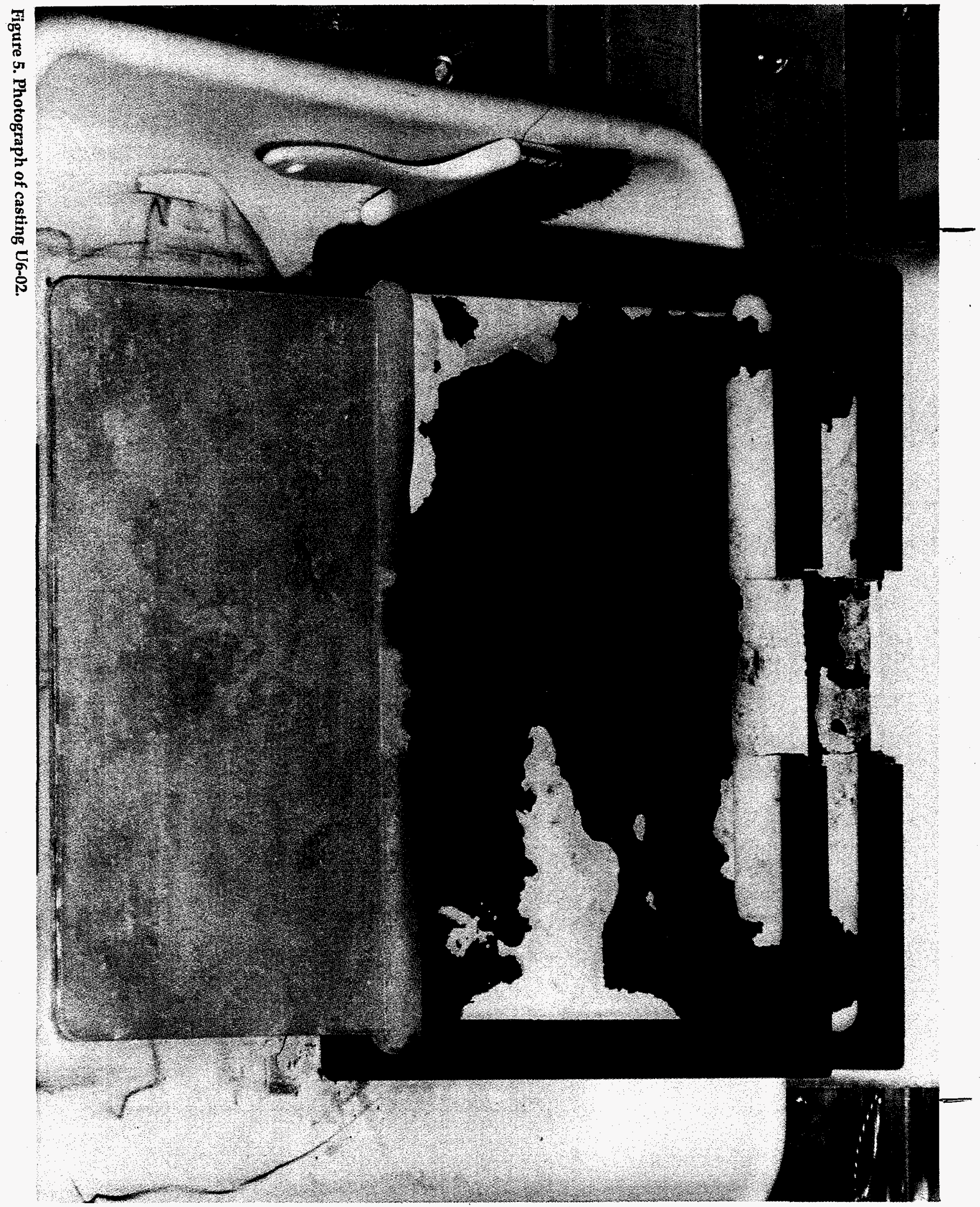




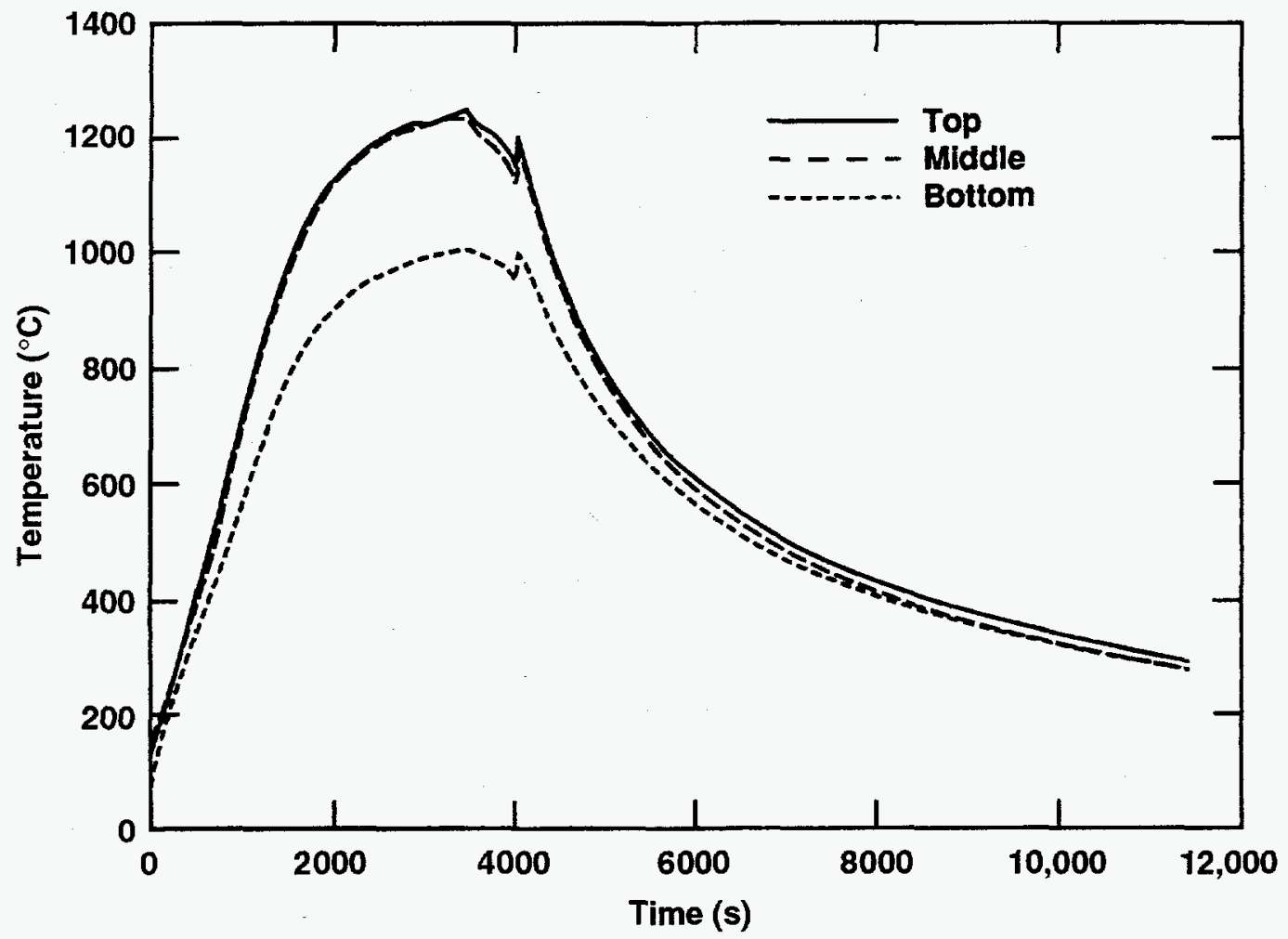

Figure 6. Top- middle- and bottom-center thermal histories for casting U6-06.

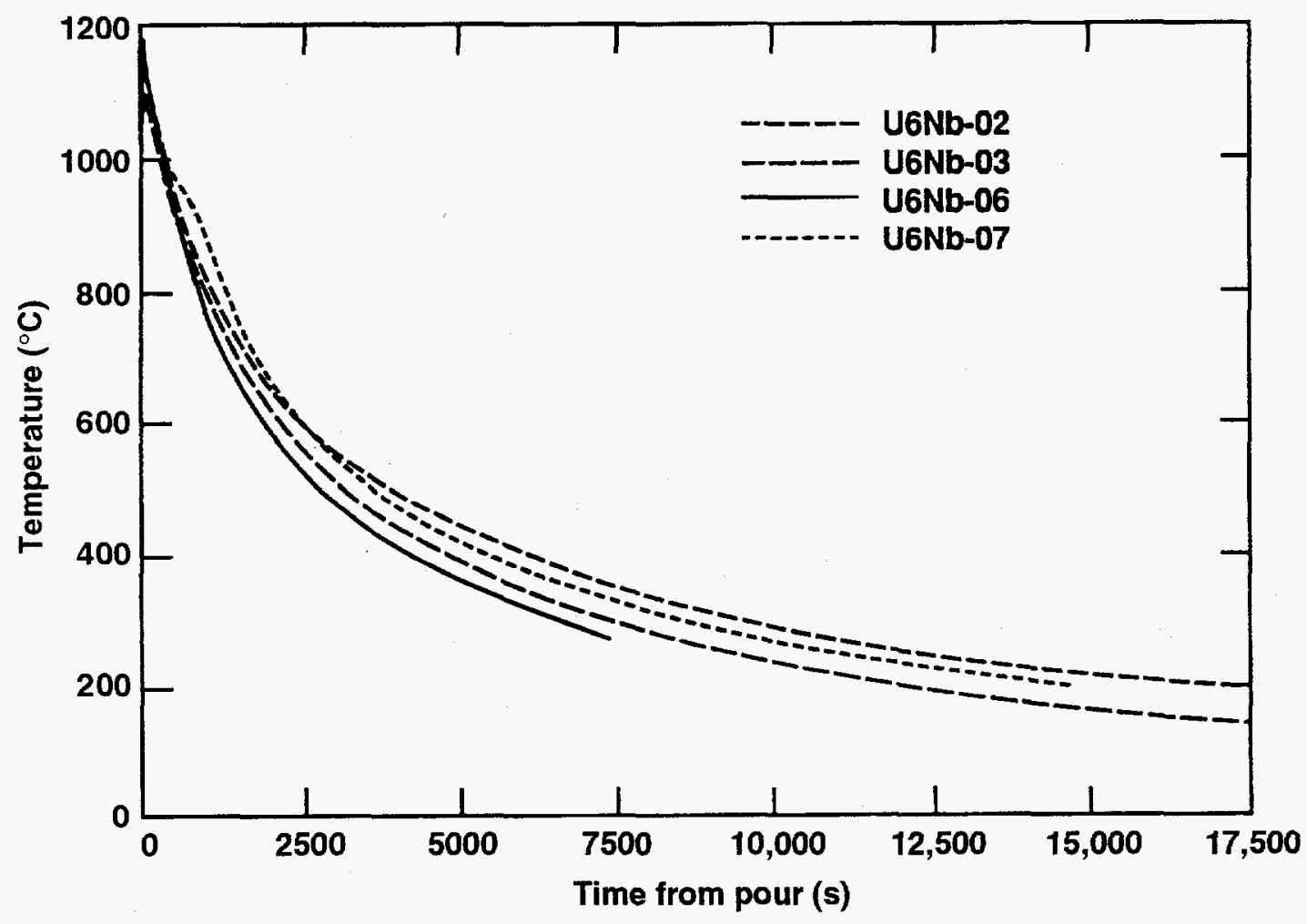

Figure 7. Middle-center temperature as a function of time from pour for all castings. 


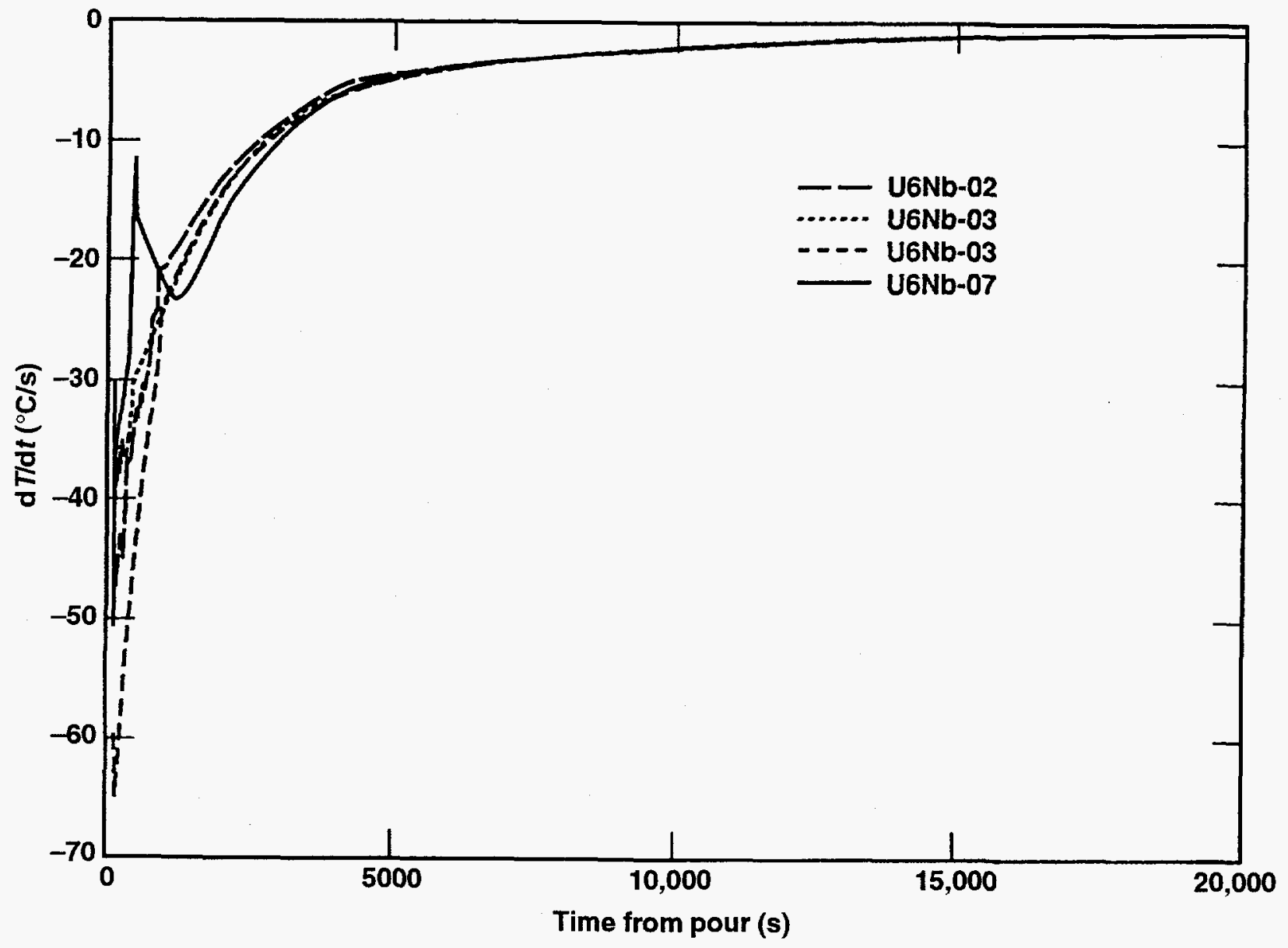

Figure 8. Cooling rates, $d T / d t$, of the curves in Fig. 6 as a function of time from pour. 
(a)

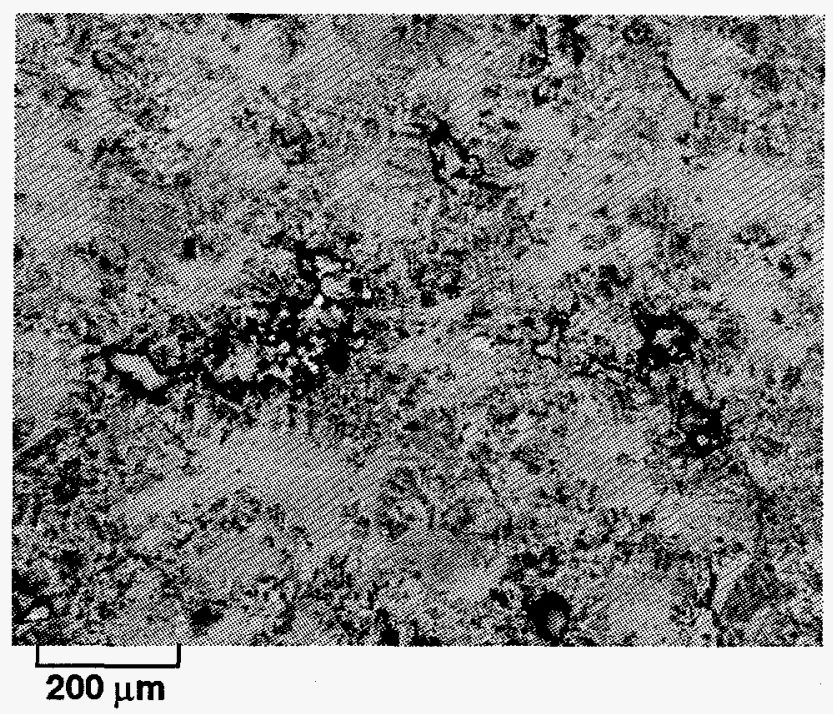

(b)

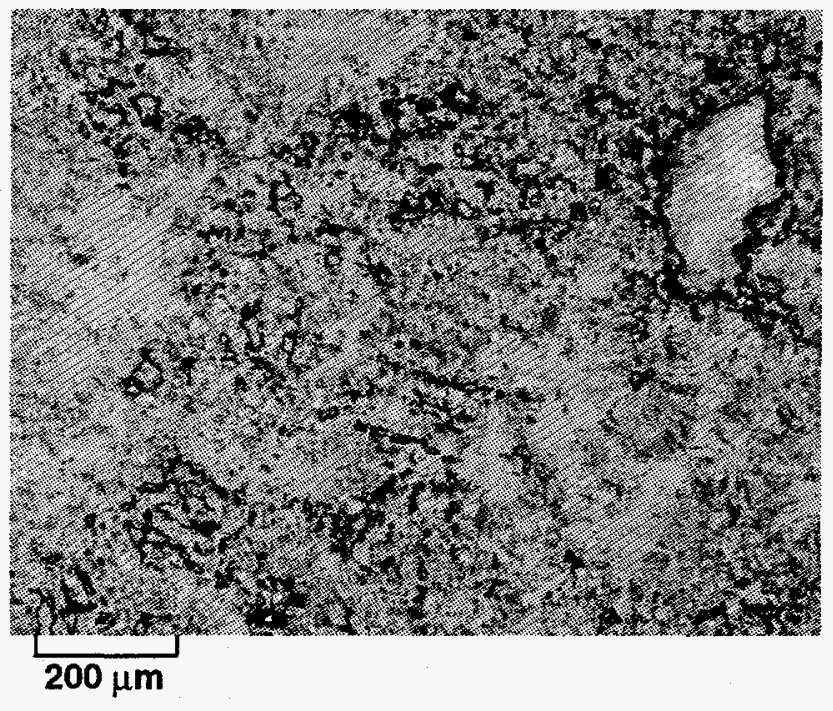

(c)

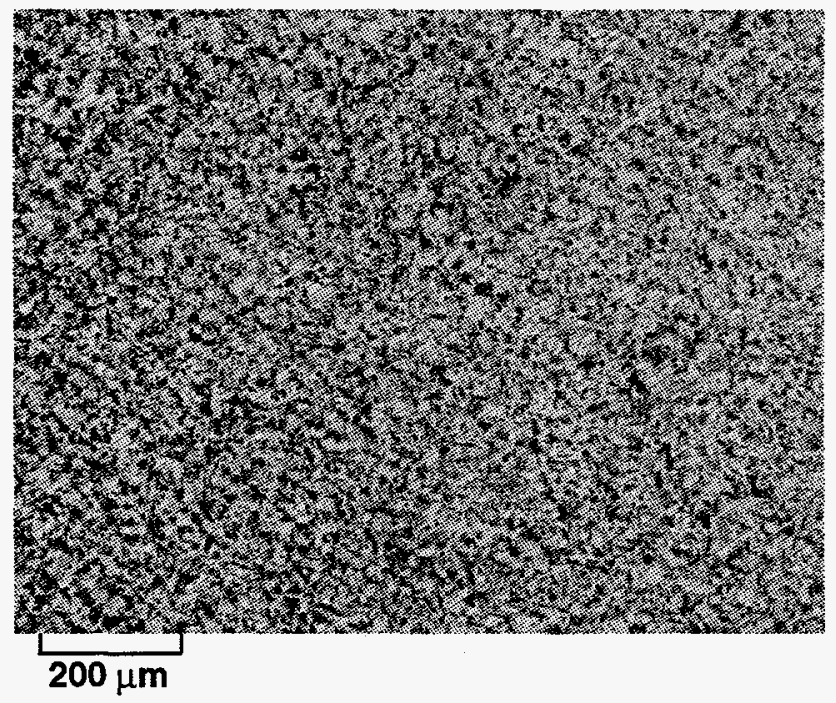

Figure 9. Optical micrographs of casting U6-02: (a) top, near the header bar; (b) center; (c) bottom. The sections were diamond polished and oxidized in air to reveal microstrutural features. 
(a)

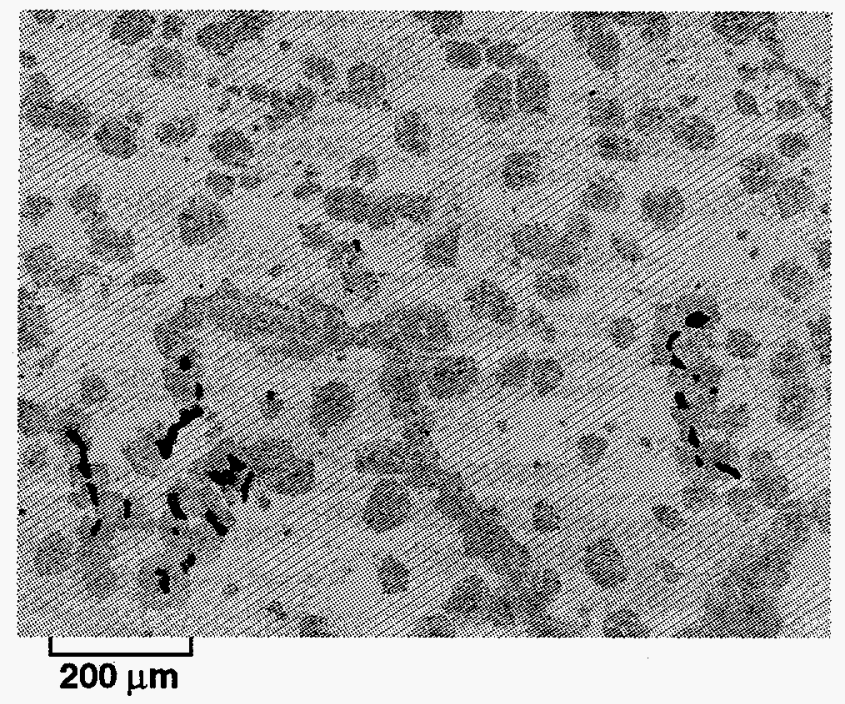

(b)

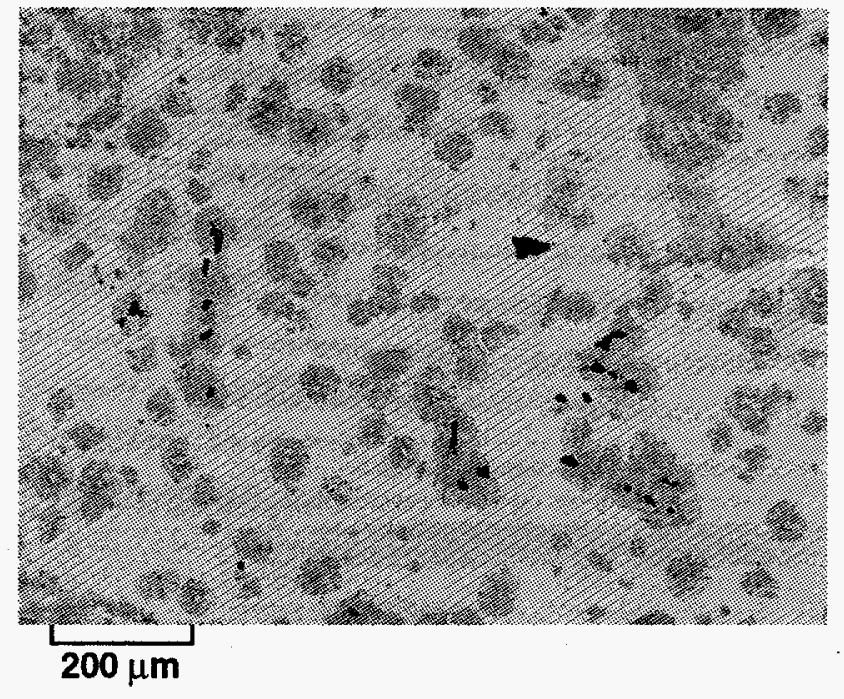

(c)

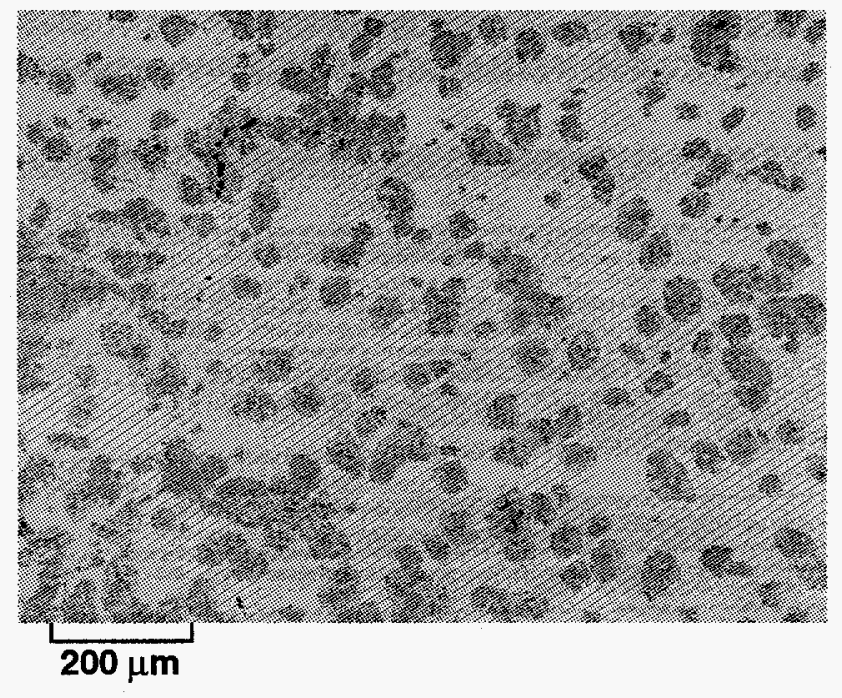

Figure 10. Optical micrographs of casting U6-03: (a) top, near the header bar; (b) center; (c) bottom. The sections were diamond polished and oxidized in air to reveal microstrutural features. 
(a)

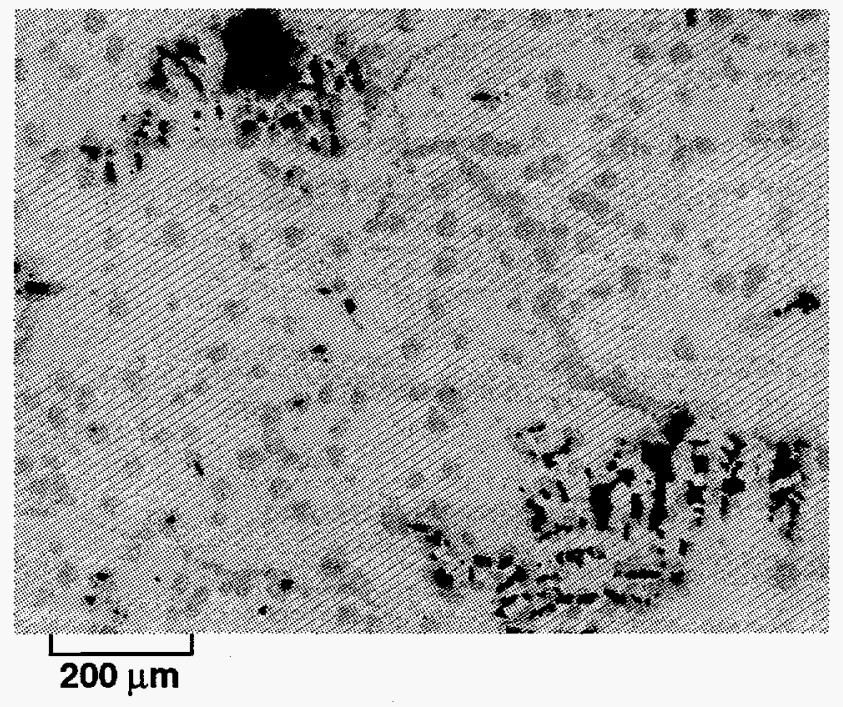

(b)

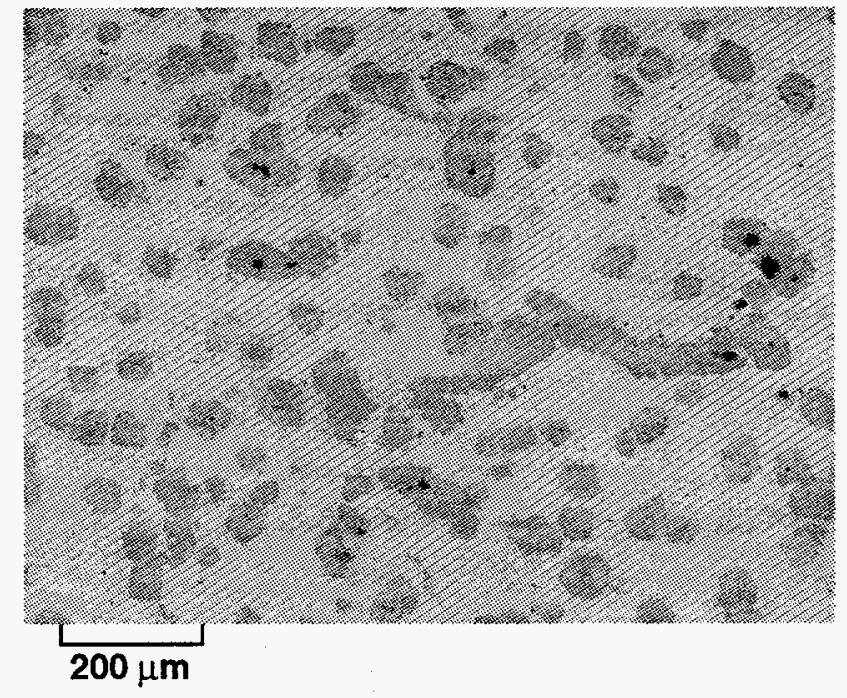

(c)

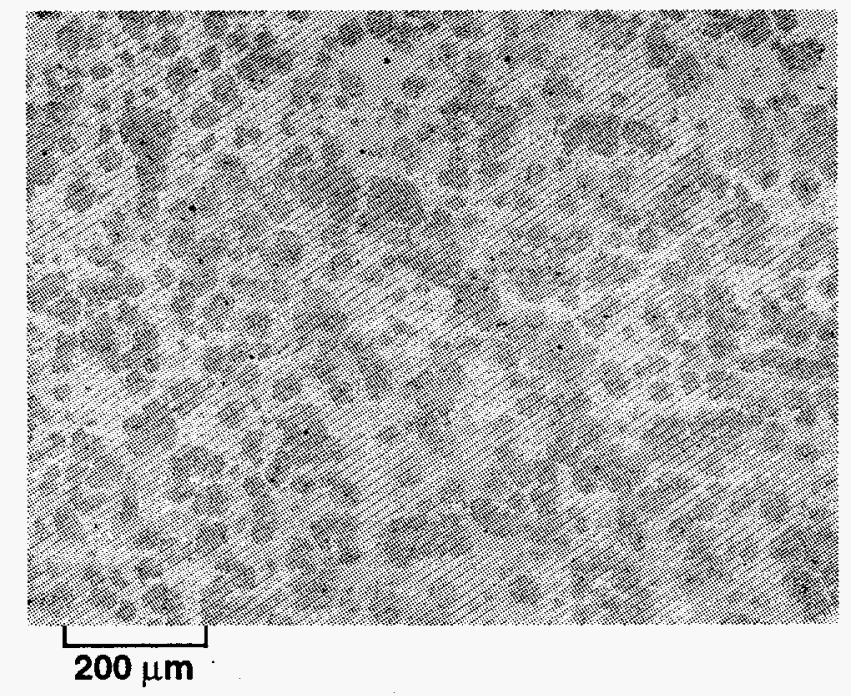

Figure 11. Optical micrographs of casting U6-06: (a) top, near the header bar; (b) center; (c) bottom. The sections were diamond polished and oxidized in air to reveal microstrutural features. 


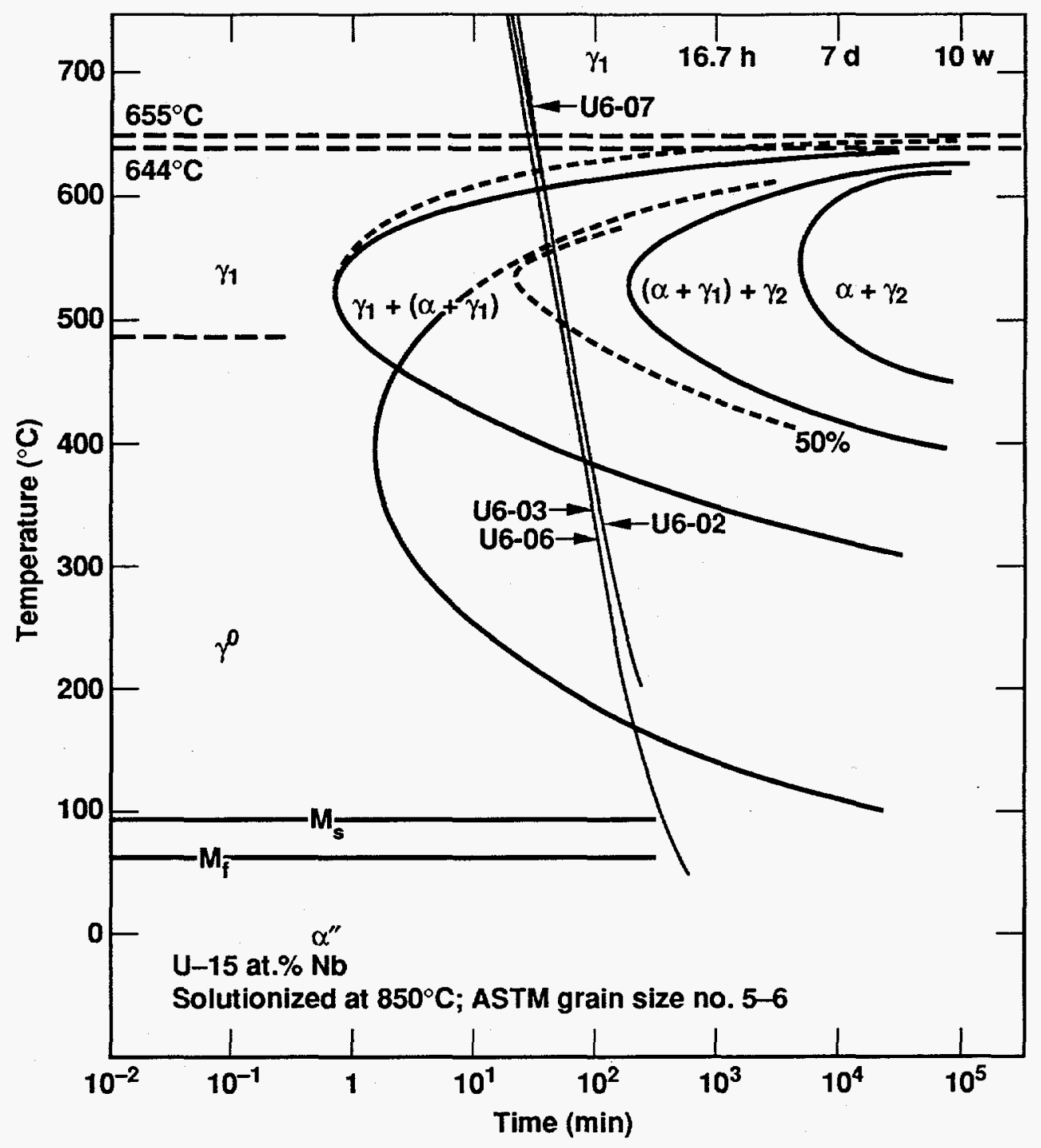

Figure 12. Time-temperature-transformation diagram for $\mathrm{U}-6 \mathrm{Nb}$. Cooling curves for the middle-center of castings U6-02, -03 , and -06 are also shown. 


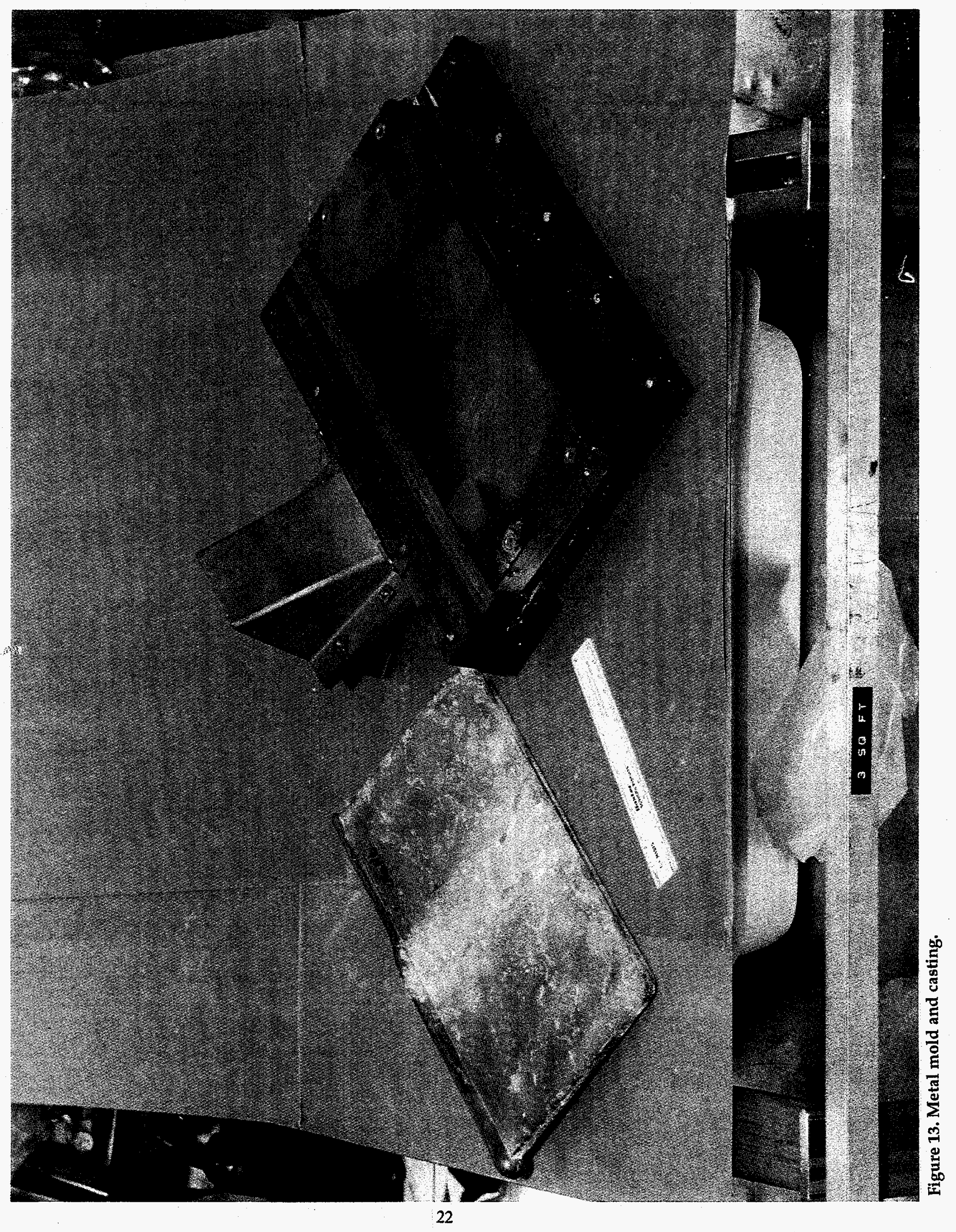




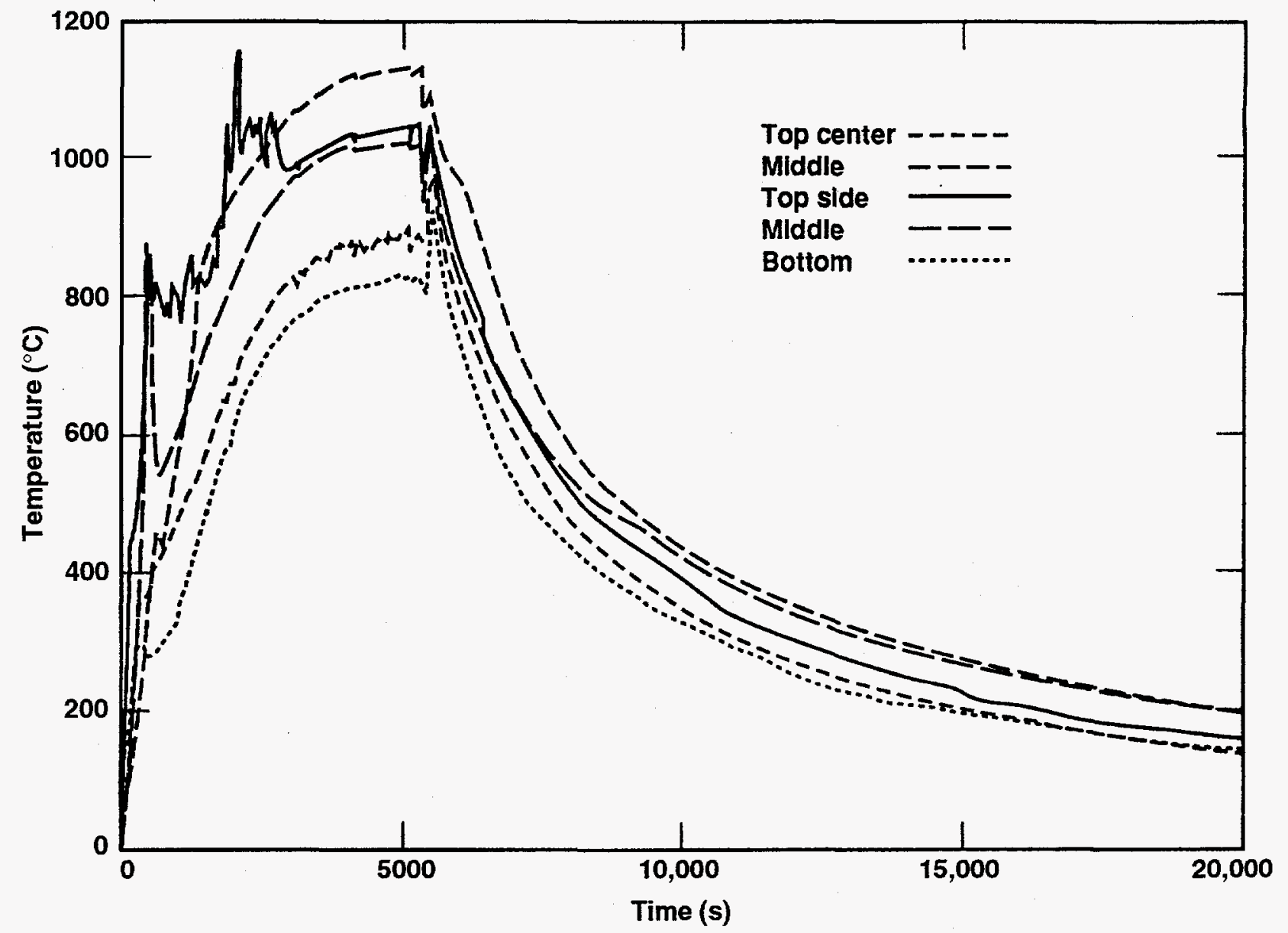

Figure 14. Top- and middle-center and top-, middle-, and bottom-side thermal histories for casting U6-07. The bottom-center thermocouple failed. 


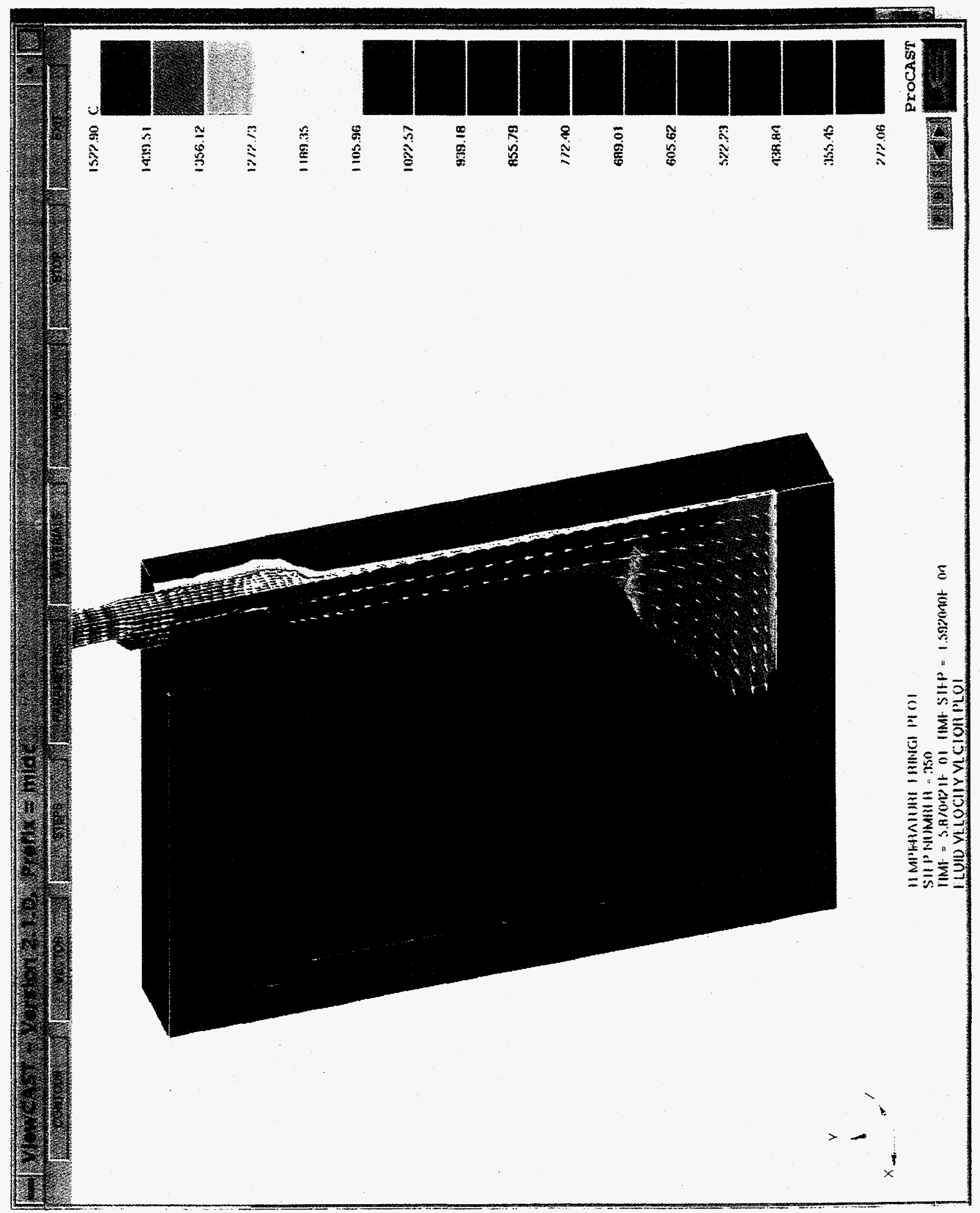

Figure 15. Analysis of U-6Nb poured into a graphite mold: $0.59 \mathrm{~s}$ after the pour. 


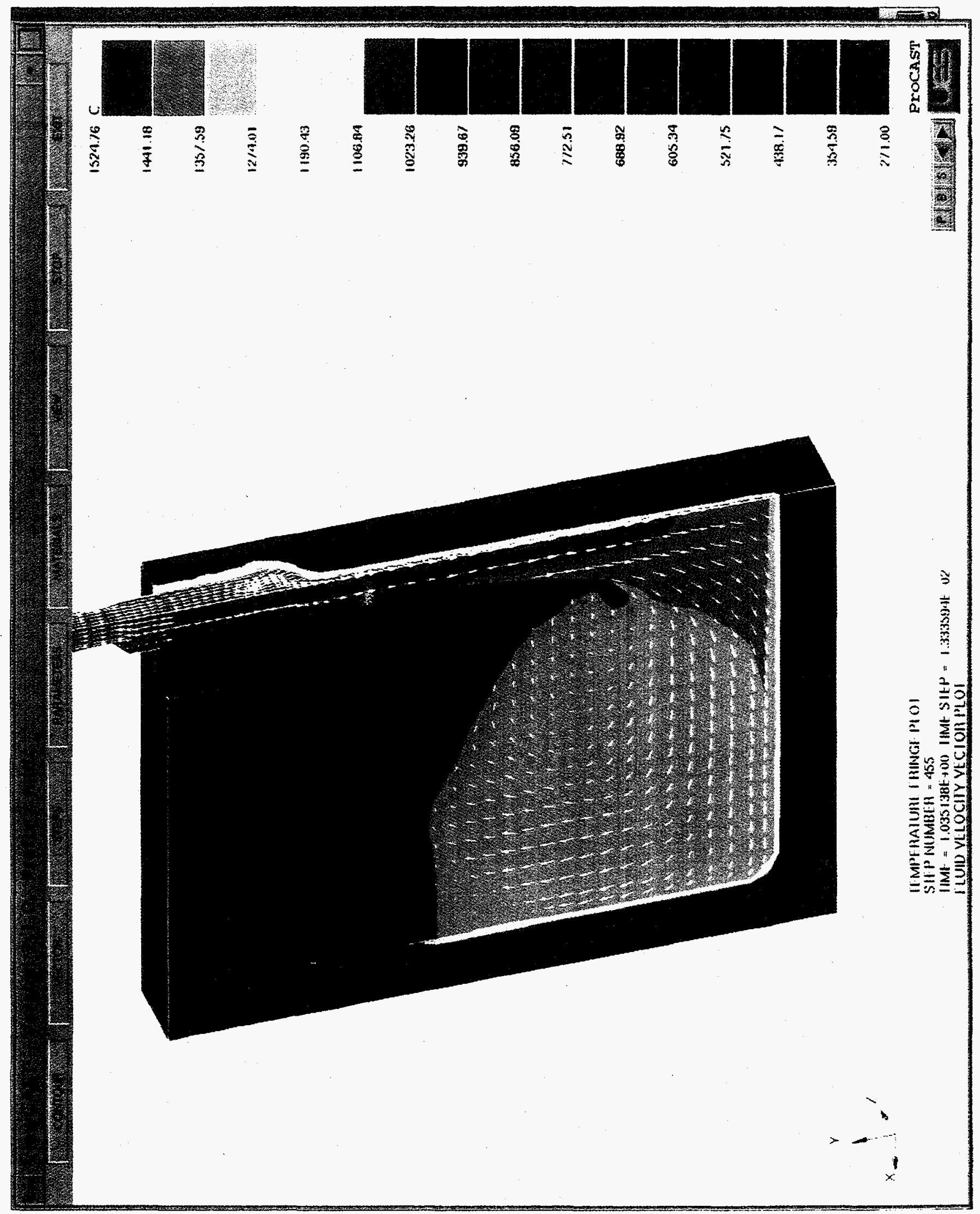

Figure 16. Analysis of $\mathrm{U}-6 \mathrm{Nb}$ poured into a graphite mold: $1.04 \mathrm{~s}$ after the pour. 


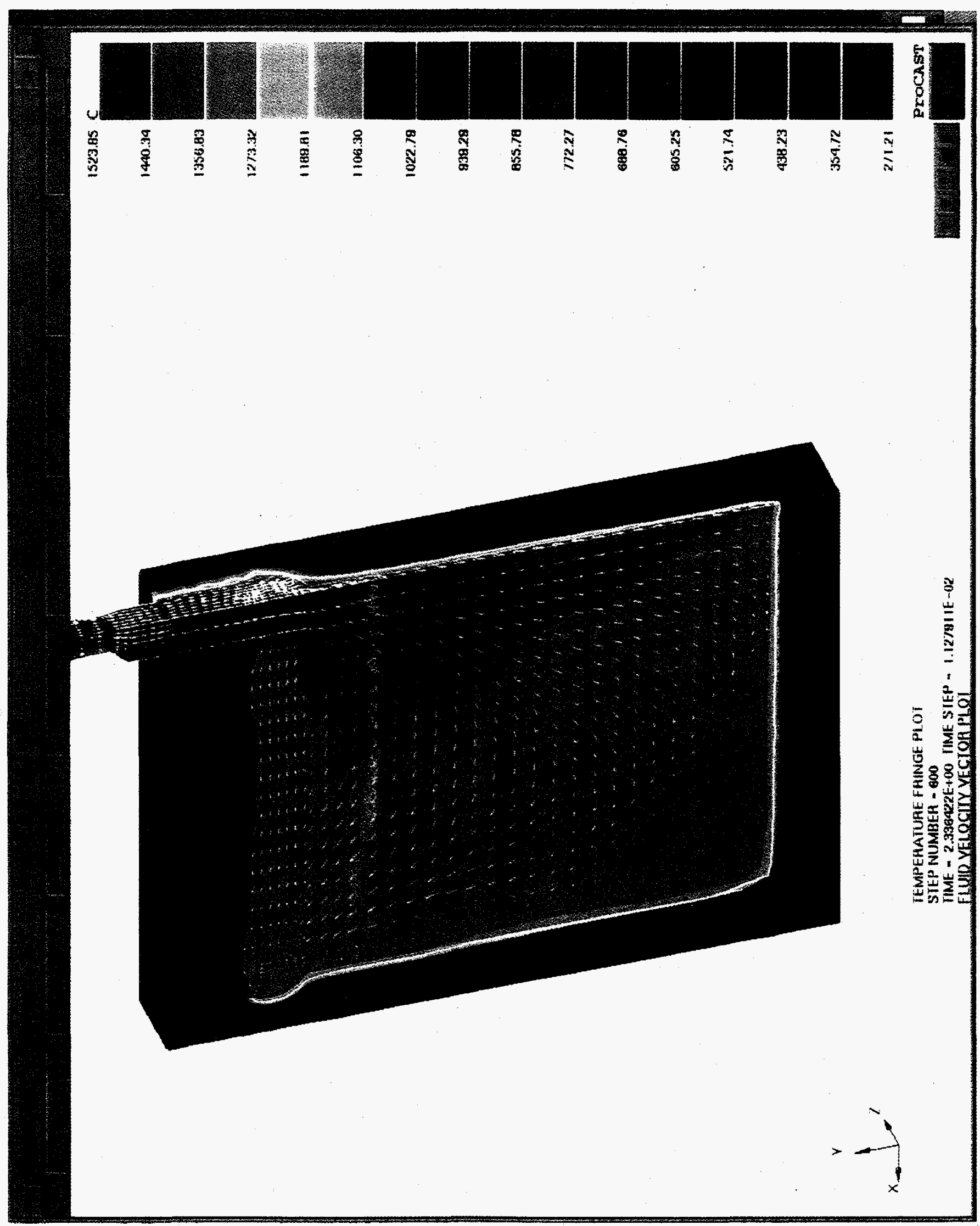

Figure 17. Analysis of $\mathrm{U}-6 \mathrm{Nb}$ poured into a graphite mold: $2.34 \mathrm{~s}$ after the pour. 


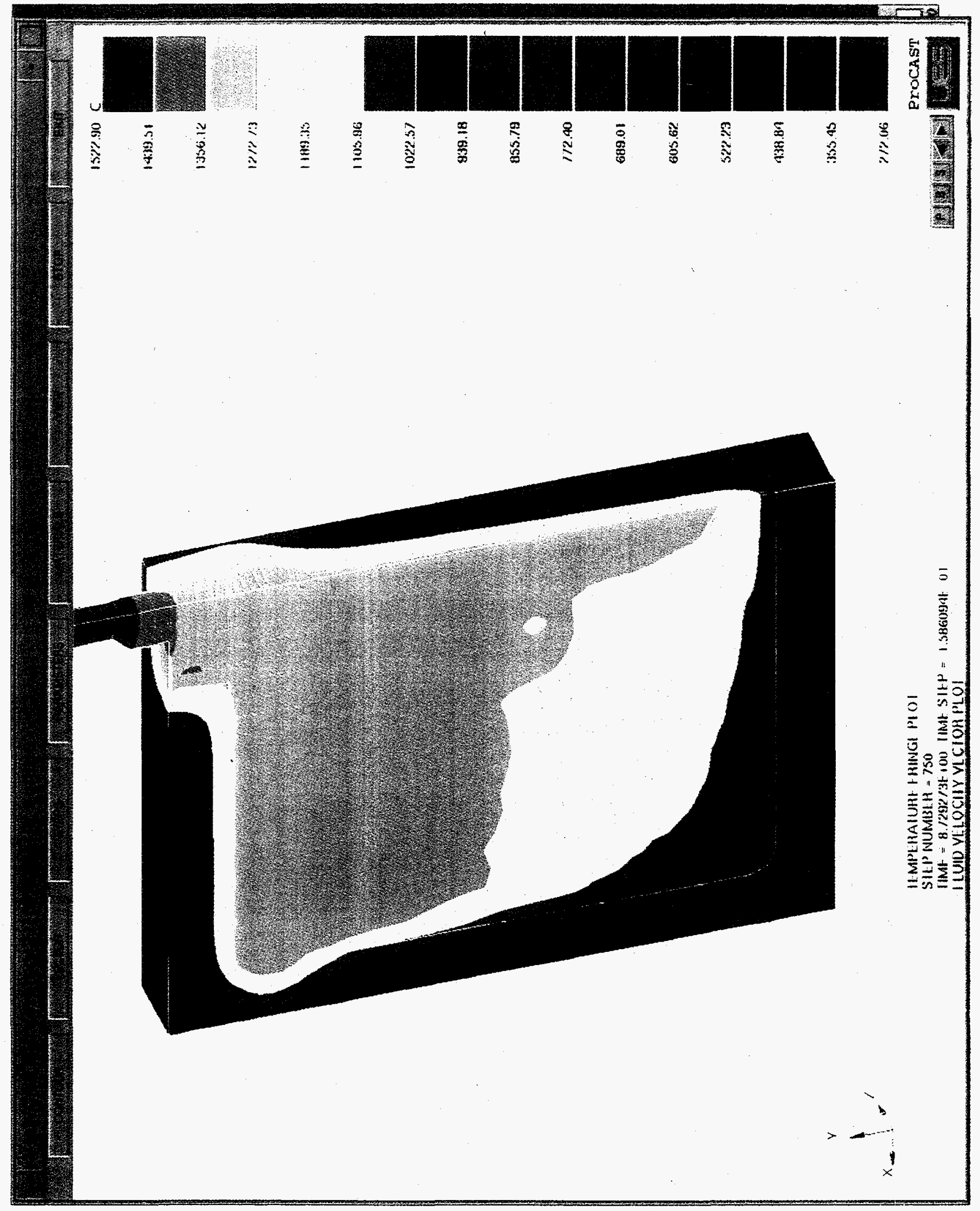

Figure 18. Analysis of $\mathrm{U}-6 \mathrm{Nb}$ poured into a graphite mold: $8.73 \mathrm{~s}$ after the pour. 


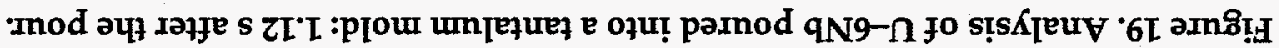

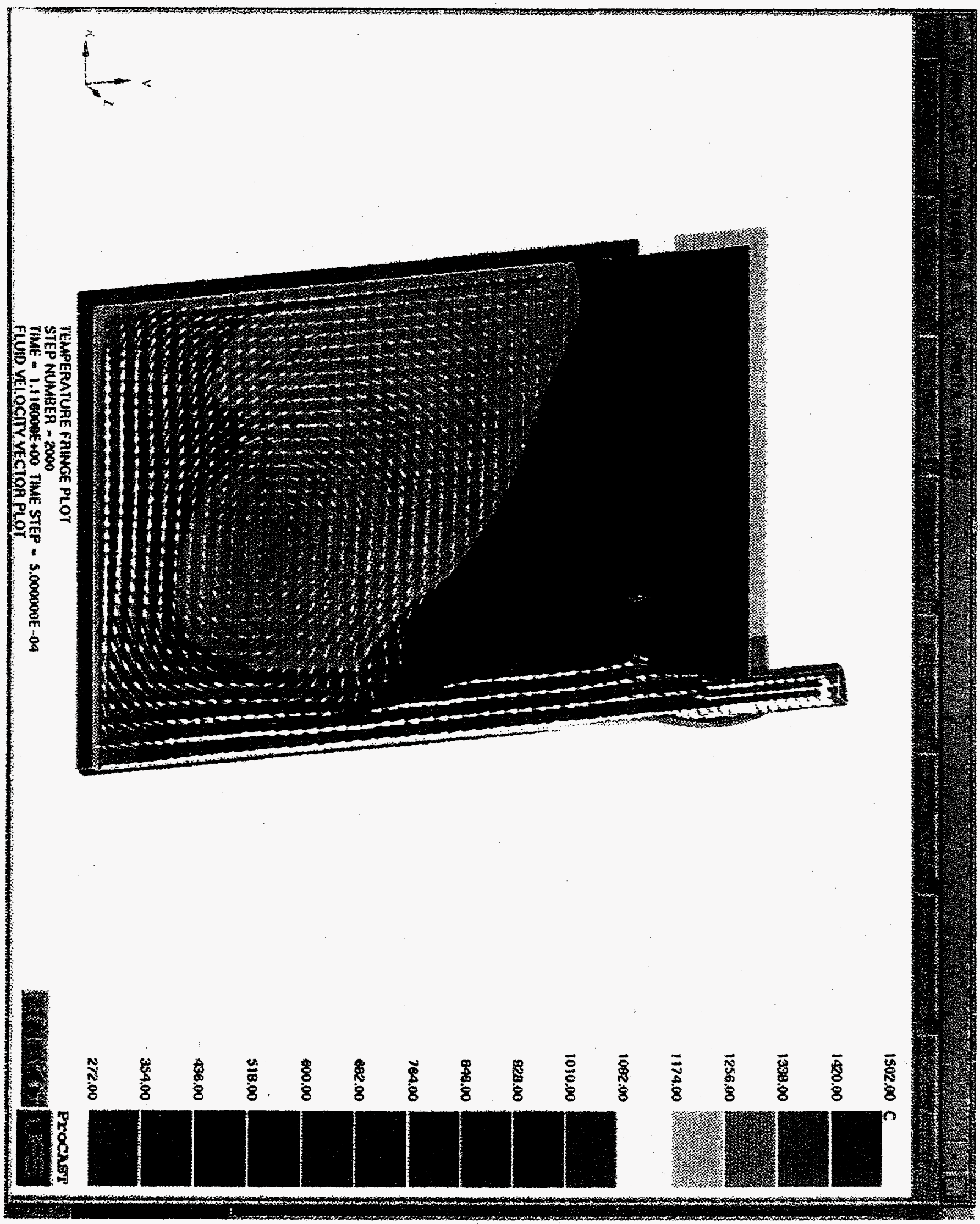




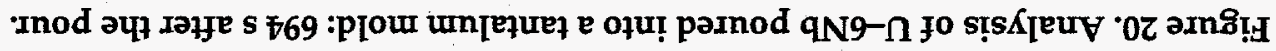

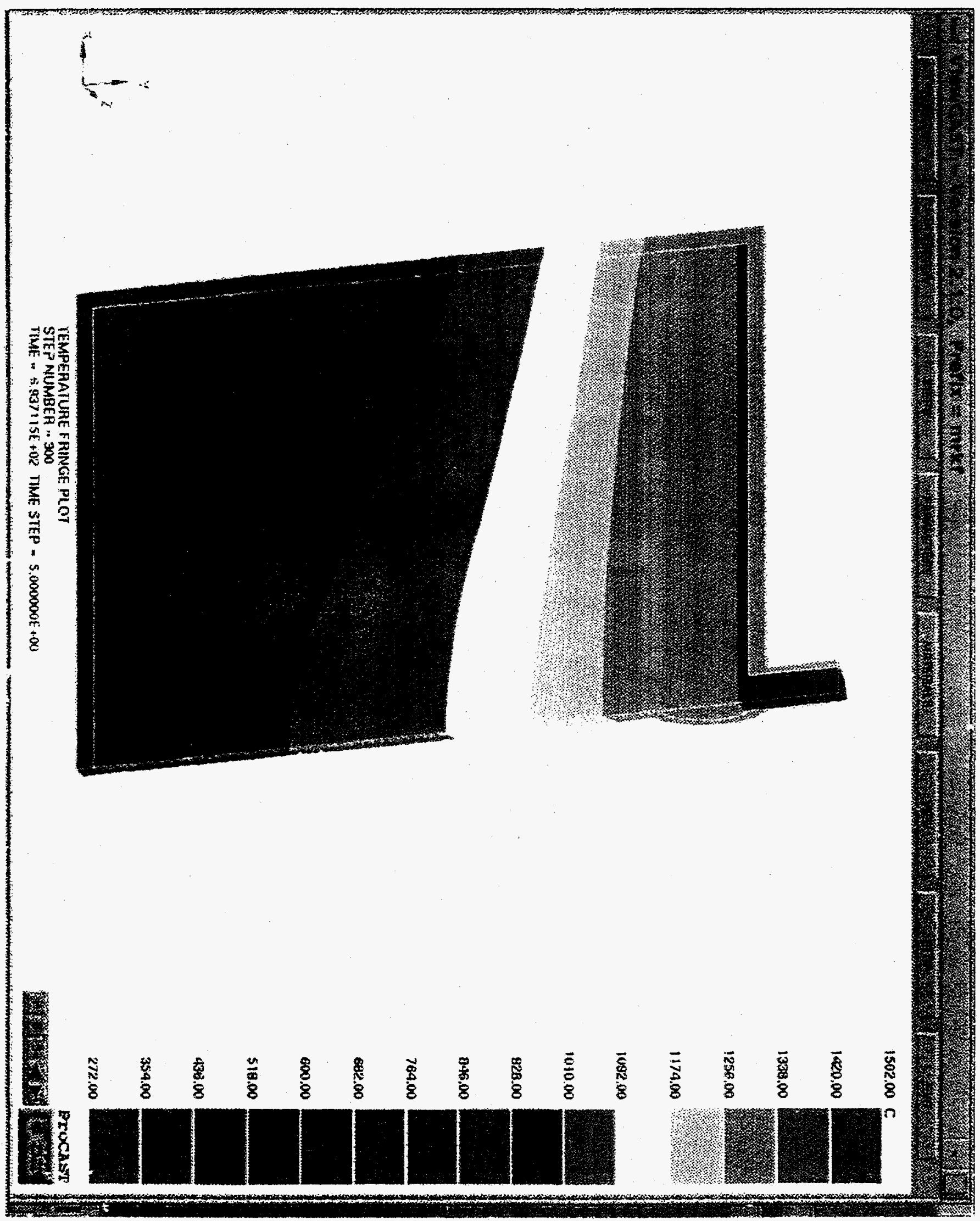



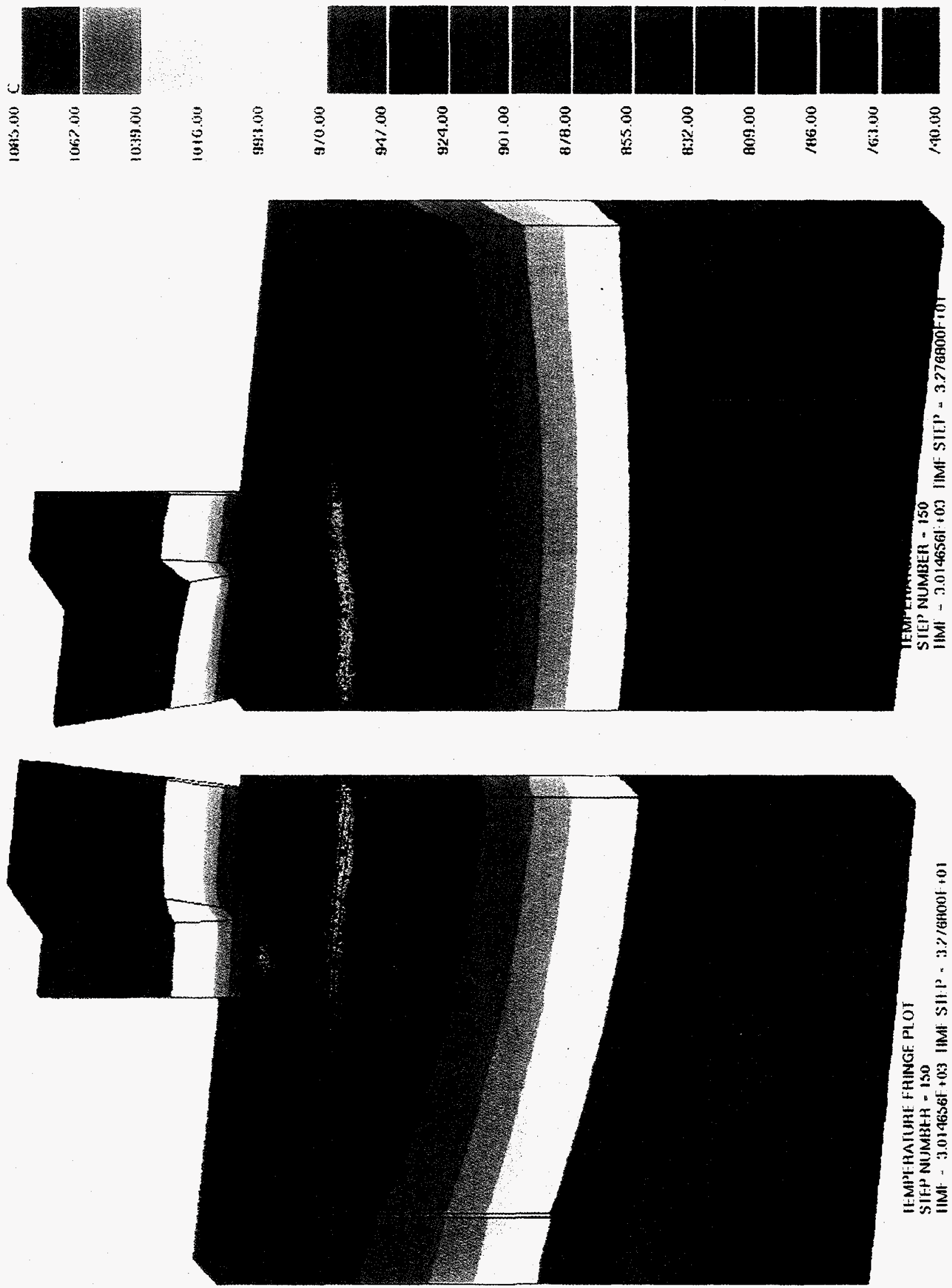

Figure 21. Initial mold temperatures for a graphite mold. 


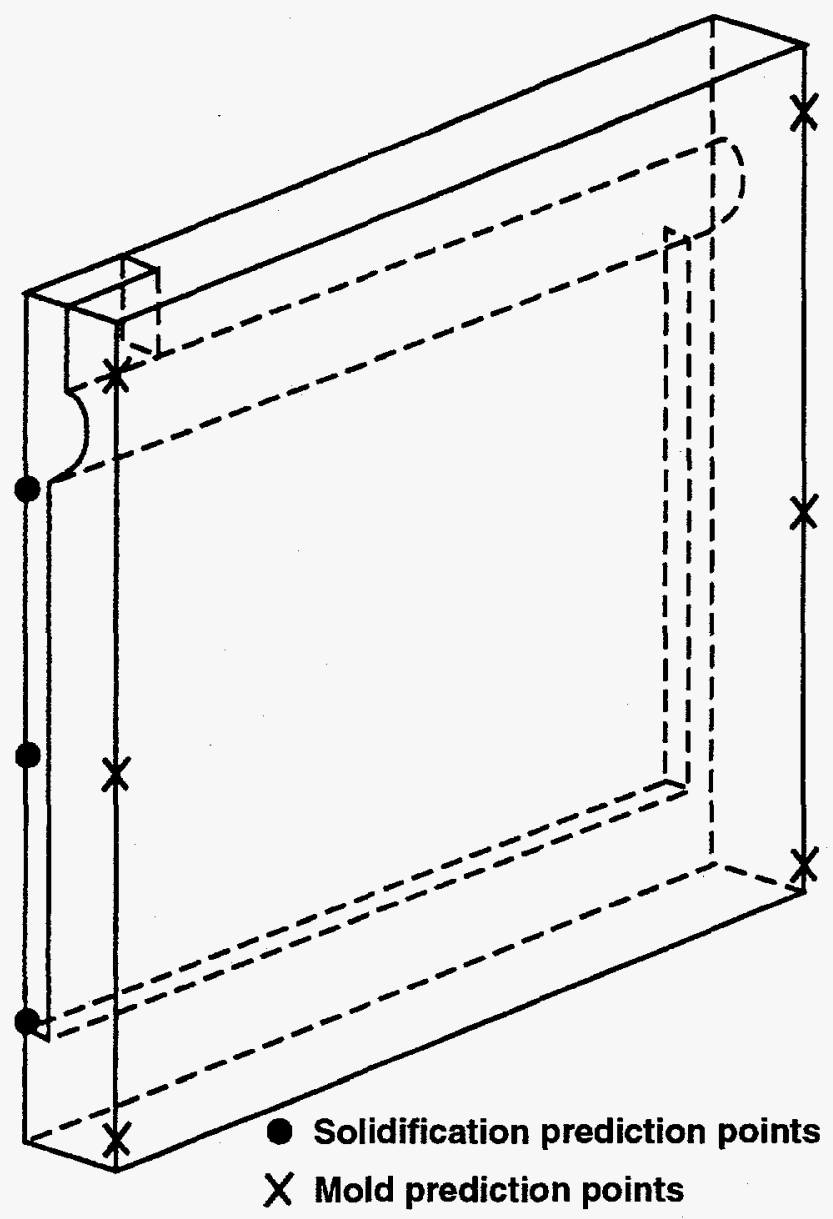

Figure 22. Locations of reference points for mold temperatures and melt solidification. 


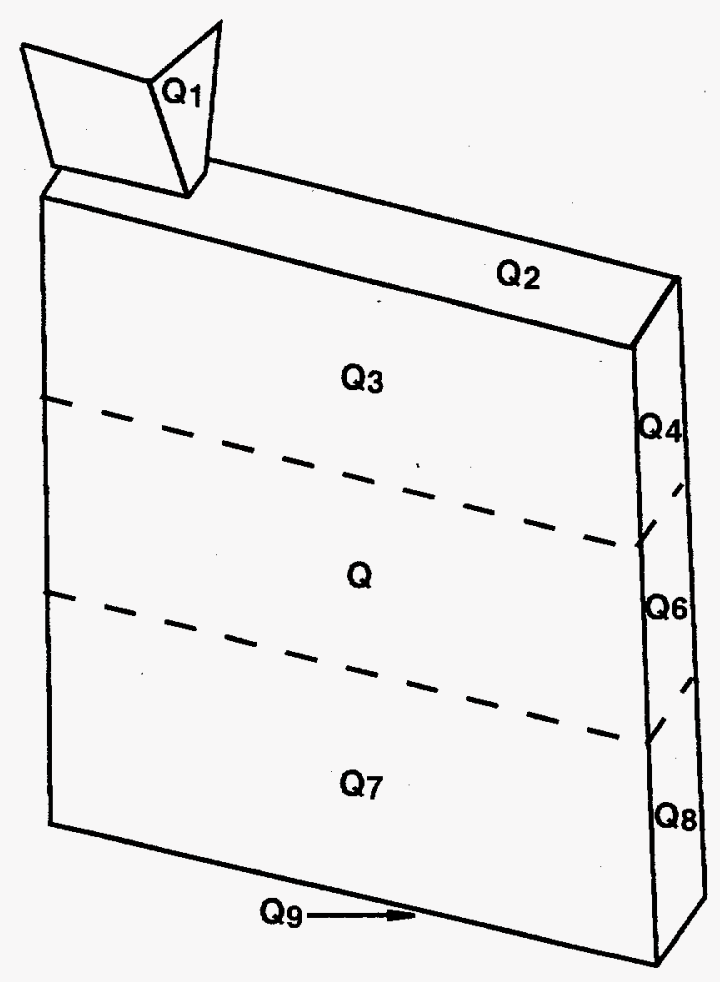

\begin{tabular}{|ccc|}
\hline Zone & $\begin{array}{c}\text { Heat flux } \\
\left(\mathbf{k W} / \mathbf{m}^{2}\right)\end{array}$ & $\begin{array}{c}\text { Radiant } \\
\text { emission }\end{array}$ \\
\hline$Q_{1}$ & 22.0 & 0.27 \\
$Q_{2}$ & 26.0 & 0.27 \\
$Q_{3}$ & 92.0 & 0.27 \\
$Q_{4}$ & 69.0 & 0.45 \\
$Q_{5}$ & 112.3 & 0.27 \\
$Q_{6}$ & 80.0 & 0.60 \\
$Q_{7}$ & 0 & 0.19 \\
$Q_{8}$ & 0 & 0.92 \\
$Q_{9}$ & 0 & 0.60 \\
\hline
\end{tabular}

Figure 23. Thermal-boundary conditions for the analysis of a graphite mold. 


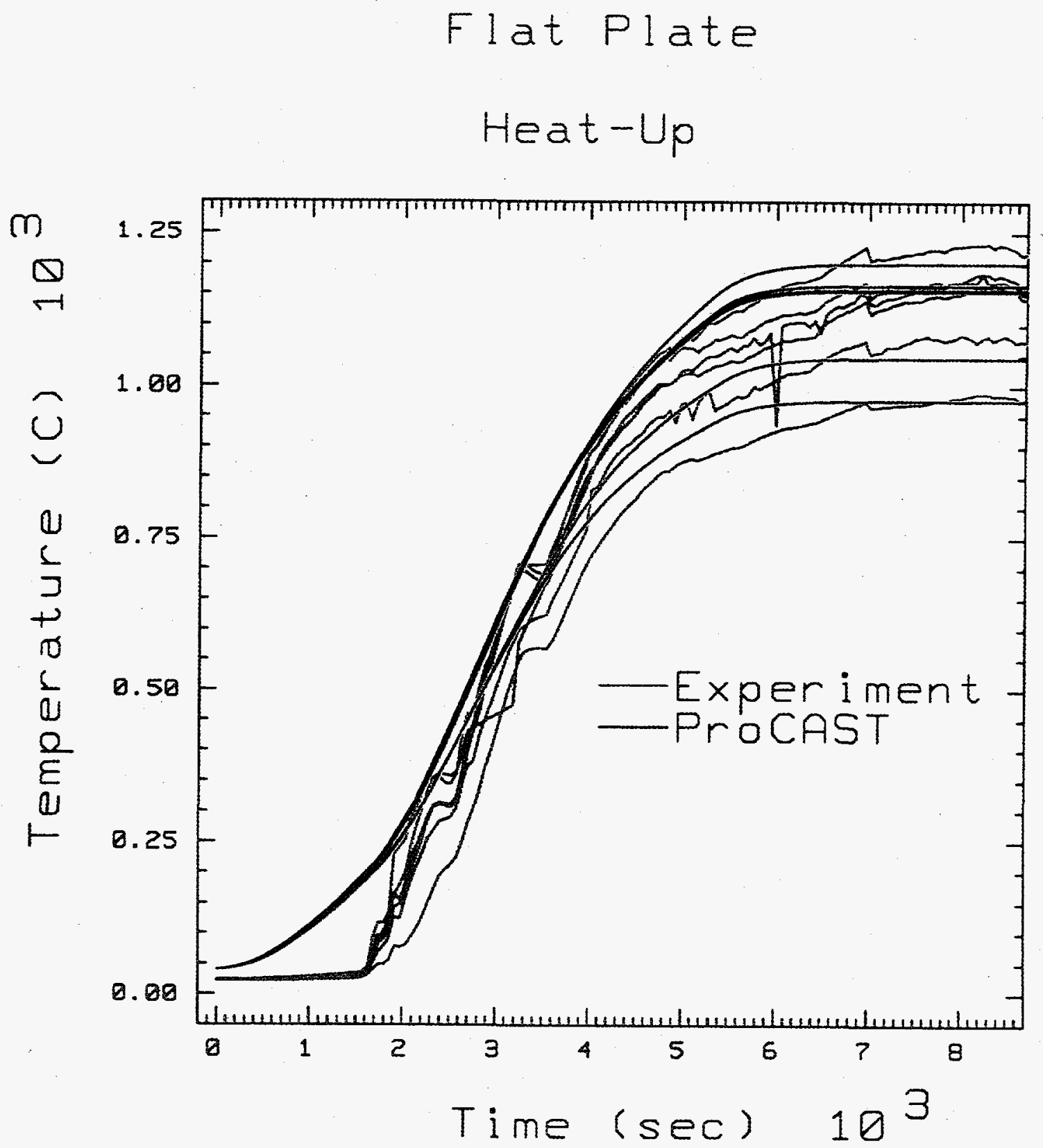

Figure 24. Steady-state calculations of mold heating compared with thermocouple measurements for experiment U6-02. 


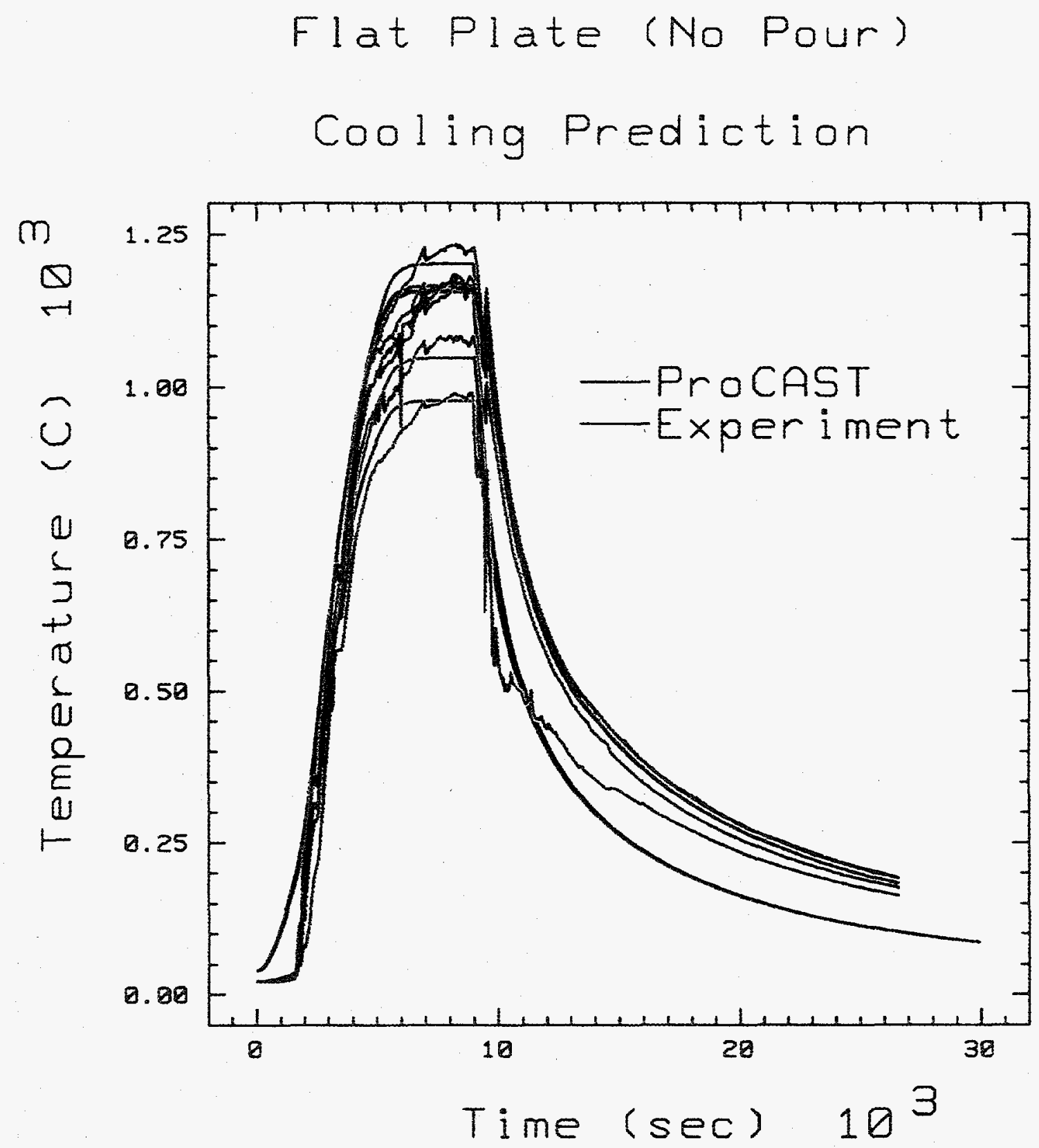

Figure 25. Calculations of the heating and cooling of agraphite mold without liquid metal, compared with experiment. 
Flat Plate

Cooling Prediction

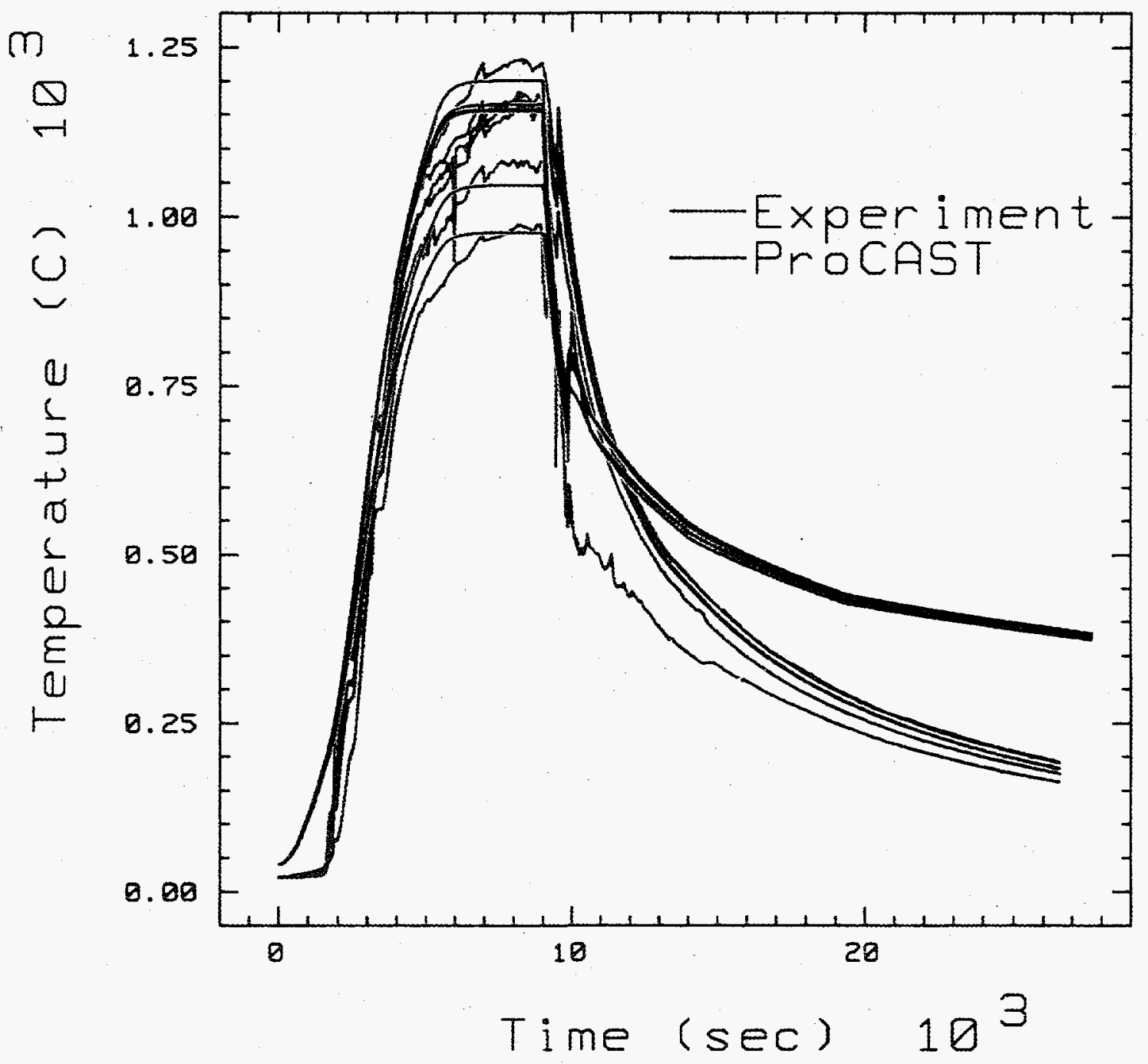

Figure 26. Calculations of the heating and cooling of experiment U6-02 compared with thermocouple measurements: total time lapse. 


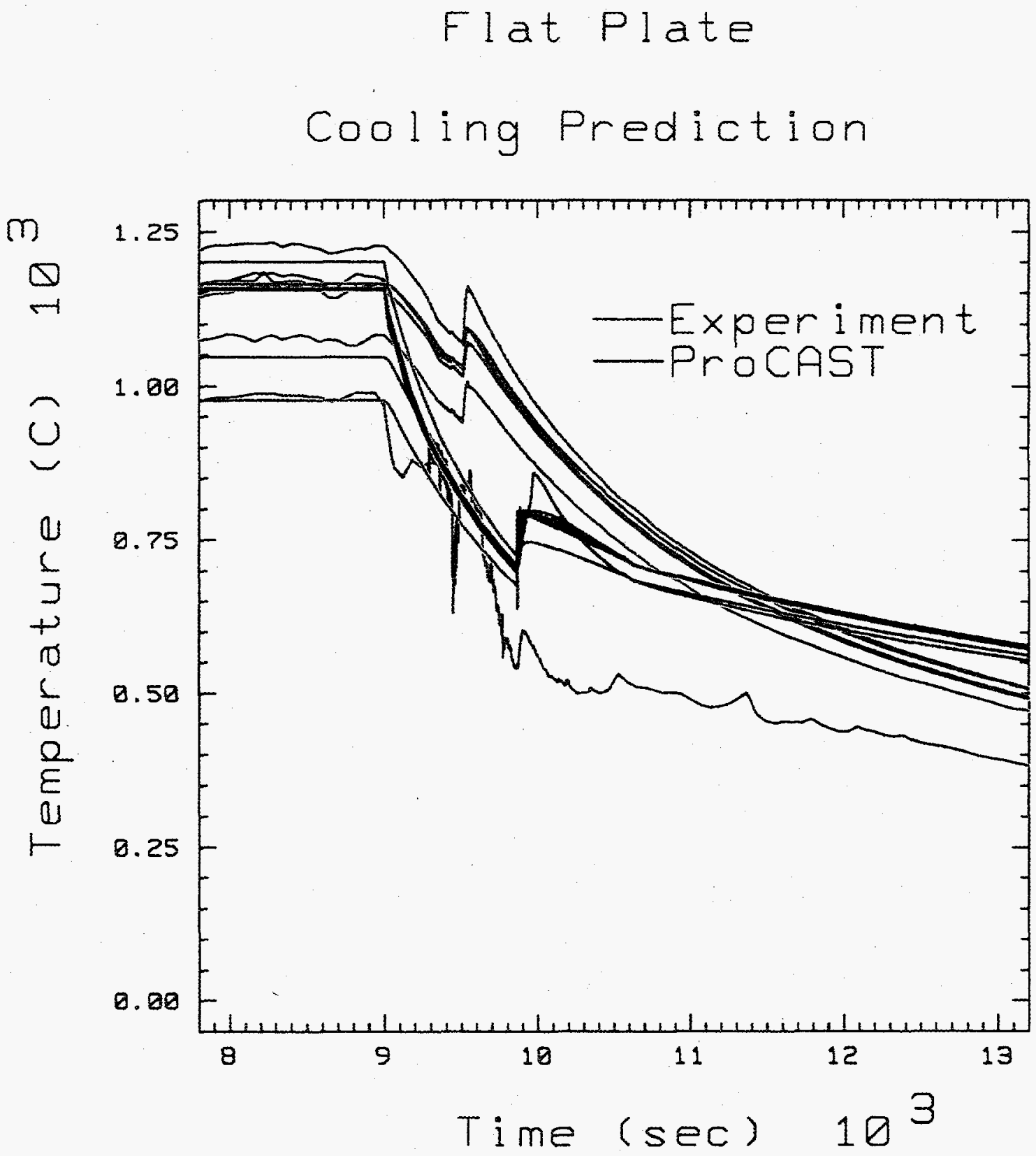

Figure 27. Cooling of experiment U6-02 near pour time. 